DOI : $10.24850 / \mathrm{j}-$ tyca-2022-02-04

Artículos

\title{
Instrumentación hidráulica y su aplicación a las ecuaciones de Nikuradse y PrandtI-Von Kármán, para la estimación de la rugosidad compuesta en túneles de desvío. Caso de estudio: río Grijalva \\ Hydraulic instrumentation and its application to the Nikuradse and Prandtl-Von Kármán, equations for the estimation of composite roughness in diversion tunnels Case study: Grijalva River
}

Ana Alicia Palacios-Fonseca1, ORCID: https://orcid.org/0000-00019860-8345

Humberto Marengo-Mogollón², ORCID: https://orcid.org/0000-00018829-4020

${ }^{1}$ Instituto Mexicano de Tecnología del agua, Jiutepec, Morelos, México, ana_palacios@tlaloc.imta.mx

${ }^{2}$ Facultad de Ingeniería, Universidad Nacional Autónoma de México, Ciudad de México, México, hmarengom@gmail.com 


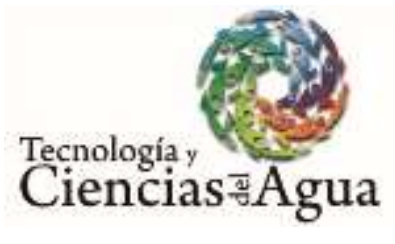

2022, Instituto Mexicano de Tecnología del Agua

Open Access bajo la licencia CC BY-NC-SA 4.0 (https://creativecommons.org/licenses/by-nc-sa/4.0/)

Autora para correspondencia: Ana Alicia Palacios-Fonseca, ana_palacios@tlaloc.imta.mx, anapalf27@gmail.com

\section{Resumen}

En los recientes proyectos hidroeléctricos construidos en México (P.H. El Cajón, P.H. La Yesca y túneles del río Grijalva) se han diseñado las obras de desvío con una combinación de materiales: concreto hidráulico en su plantilla y concreto lanzado en sus paredes y bóveda, lo que permite reducir las pérdidas hidráulicas y obtener una mayor capacidad de descarga para garantizar la seguridad hidrológica de la presa durante el tiempo de construcción, además de lograr considerables ahorros en los costos. Para monitorear dicha capacidad se han realizado diversos proyectos de instrumentación, lo que permite registrar las variables hidráulicas en diferentes secciones, además de estimar el parámetro representativo de la rugosidad compuesta.

Este artículo trata sobre la estimación del parámetro de rugosidad compuesta en túneles de desvío con caso de estudio: "túneles de comunicación del río Grijalva", localizados aguas arriba de la Central Hidroeléctrica Peñitas, utilizando instrumentación hidráulica que permite medir, entre otras variables, la velocidad en la zona cercana a la pared. Y aplicando las teorías de capa límite de Nikuradse y de Prandtl-Von Kármán determinar la rugosidad equivalente en las paredes, así como la 


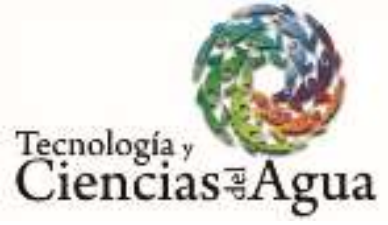

2022, Instituto Mexicano de Tecnología del Agua

Open Access bajo la licencia CC BY-NC-SA 4.0 (https://creativecommons.org/licenses/by-nc-sa/4.0/)

revisión de 17 ecuaciones empíricas para obtener finalmente la rugosidad compuesta representativa de los túneles.

Palabras clave: instrumentación hidráulica, rugosidad compuesta, túneles de desvío, perfiles de velocidad, Nikuradse, Prandtl-Von Kármán, capa límite, flujo a superficie libre, seguridad de presas.

\section{Abstract}

In the recent hydroelectric power plants built in Mexico (P.H. El Cajón, P.H. La Yesca, and Grijalva River tunnels), the diversion tunnels have been designed with a combination of materials: hydraulic concrete in its template and concrete cast in its walls and vault, which allows to reduce hydraulic losses and get a greater discharge capacity to guarantee the hydrological safety of the dam during the build time, in addition to achieving considerable cost savings. To monitor this capacity, several instrumentation projects have been carried out, recording the hydraulic variables in different sections, in addition to estimating the representative parameter of the composite roughness.

This article relates how estimates the composite roughness parameter in diversion tunnels, in a case study: "Communication tunnels of the Grijalva River", upstream of the Penitas Hydroelectric Power Plant, using hydraulic instrumentation to measure, among other variables, the speed in the area near to the wall. And applying the boundary layer theories of Nikuradse and Prandtl-Von Kármán to determine the 
2022, Instituto Mexicano de Tecnología del Agua

Open Access bajo la licencia CC BY-NC-SA 4.0

(https://creativecommons.org/licenses/by-nc-sa/4.0/)

equivalent roughness in the walls, as well as the review of 17 empirical equations to finally obtain the representative composite roughness of the tunnels.

Keywords: Hydraulic instrumentation, composite roughness, diversion tunnels, velocity profiles, Nikuradse, Prandtl-Von Kármán, boundary layer, free-surface flow, dam safety.

Recibido: 04/03/2020

Aceptado: 01/03/2021

\section{Introducción}

La Comisión Federal de Electricidad (CFE), a través de la Coordinación de Proyectos Hidroeléctricos ( $\mathrm{CPH}$ ) y del Laboratorio de Hidráulica, ha llevado a cabo desde 2008 diversos proyectos de instrumentación hidráulica, en el P.H. El Cajón, P.H. La Yesca y los túneles del río Grijalva. En el P.H. La Yesca se instrumentaron diversas estructuras para estudiar su comportamiento hidráulico: las obras de desvío; la obra de generación, el 


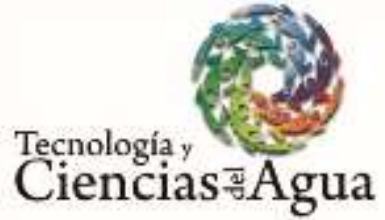

2022, Instituto Mexicano de Tecnología del Agua

Open Access bajo la licencia CC BY-NC-SA 4.0 (https://creativecommons.org/licenses/by-nc-sa/4.0/)

desfogue y la cámara de oscilación; la obra de excedencias; el vertedor; el río aguas abajo de la presa, y el embalse. Dichas instrumentaciones consisten principalmente en la instalación de celdas o sensores de presión, y medidores doppler para calcular la velocidad y el gasto, así como otras variables, para el estudio de la rugosidad compuesta.

En 2007, como resultado de las Iluvias acumuladas del 28 de octubre al 3 de noviembre de 2007 sobre el río Grijalva en Chiapas y que arrojó 1077 mm, se produjo un deslizamiento por margen derecha de tierra y roca de 55 millones de metros cúbicos, lo que provocó un bloqueo en el río de $800 \mathrm{~m}$ de longitud y $300 \mathrm{~m}$ de ancho, representando principalmente un serio riesgo para la seguridad de la C.H. Peñitas en caso de un rompimiento que podría generar una avenida no regulada $y$, por lo tanto, graves daños a las poblaciones aguas abajo (Marengo, 2011). Asimismo, después del deslizamiento de tierra, la conexión entre los embalses aguas arriba del caído y el de la presa Peñitas quedó reducida a un canal de $930 \mathrm{~m}$ de longitud y ancho de $70 \mathrm{~m}$ (Figura 1). 
Tecnologíay

Ciencias $\sqrt{\mathrm{v}} \mathrm{Agua}$
2022, Instituto Mexicano de Tecnología del Agua

Open Access bajo la licencia CC BY-NC-SA 4.0 (https://creativecommons.org/licenses/by-nc-sa/4.0/)

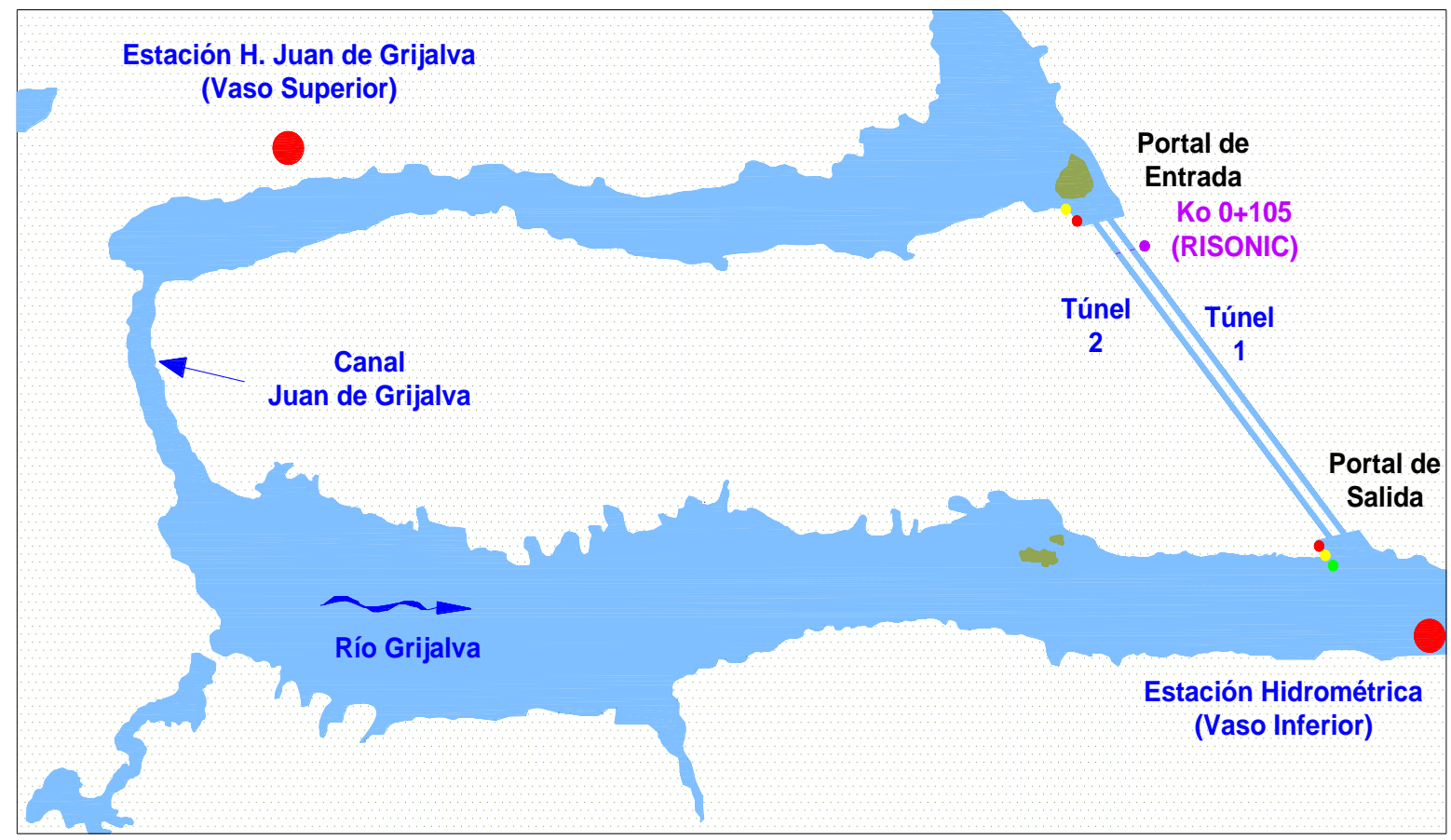

Figura 1. Localización de los túneles de comunicación del río Grijalva y el canal Juan de Grijalva después del deslizamiento.

Entre las acciones tomadas para hacer frente a caudales de hasta 3 $500 \mathrm{~m}^{3} / \mathrm{s}$ se encuentran: 1) la construcción de un canal en la zona de reducción siguiendo la traza del río; 2) la suspensión temporal de la generación de la C.H. Malpaso; 3) disminución del nivel de la C.H. Peñitas con la operación del vertedor y la generación, y 4) la construcción de dos túneles de sección portal de 14 × 14 m que complementan la capacidad de conducción del río entre la C.H. Malpaso y la C.H. Peñitas. En este último punto, dichos túneles deberían ser monitoreados en su eficiencia 


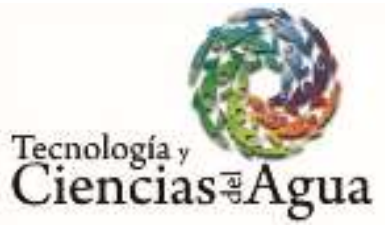

2022, Instituto Mexicano de Tecnología del Agua

Open Access bajo la licencia CC BY-NC-SA 4.0 (https://creativecommons.org/licenses/by-nc-sa/4.0/)

en la conducción hidráulica, así como en los movimientos geológicos naturales de la estructura mediante instrumentos de medición hidráulica y de geotecnia.

La instrumentación hidráulica se utilizó para medir niveles hidráulicos, velocidades de flujo en secciones definidas y gasto o caudal tanto en periodo de estiaje como de lluvias; así como para estudiar el parámetro de rugosidad compuesta representativo del túnel, lo que permitiría definir la capacidad hidráulica.

El objetivo general de este trabajo es presentar una metodología para obtener el parámetro de rugosidad compuesta representativo de los túneles de desvío en el río Grijalva a partir de mediciones directas cercanas a la pared, y posteriormente aplicar las teorías de capa límite de Prandtl-Von Kármán y la rugosidad equivalente de Nikuradse.

Los objetivos particulares son los siguientes: 1) estudiar el funcionamiento hidráulico de los túneles mediante instrumentación hidráulica; 2) estimar el parámetro de rugosidad de pared a partir de mediciones de velocidad en la zona de capa límite; 3) estimar el parámetro de rugosidad compuesta a partir de las mediciones puntuales y las teorías de capa límite de PrandtI Von-Kármán y Nikuradse; 4) analizar mediante un modelo matemático y el mínimo error cuadrado la ecuación empírica de mejor ajuste para el cálculo de rugosidad compuesta, y 5) obtener una curva gasto-rugosidades. 
2022, Instituto Mexicano de Tecnología del Agua

Open Access bajo la licencia CC BY-NC-SA 4.0

(https://creativecommons.org/licenses/by-nc-sa/4.0/)

Lo anterior podrá coadyuvar en el diseño hidráulico de obras de desvío con rugosidad compuesta y su eficiencia en la capacidad de descarga. Esta investigación se realizó en condiciones de operación real.

\section{Antecedentes}

\section{Seguridad de las obras de desvío y la rugosidad compuesta}

De acuerdo con Marengo (2019) se deben tener en cuenta algunas consideraciones al diseñar y construir las obras de desvío. Se tiene la experiencia de enero de 1992 durante la construcción del Proyecto Hidroeléctrico Aguamilpa, donde se produjeron dos avenidas extraordinarias, lo que puso a prueba las condiciones de diseño en la cortina y la obra de desvío. La obra de desvío consistió en dos túneles sección portal de 16 x 16 m y longitudes de 1100 y 1200 m (Túnel 1 y Túnel 2, respectivamente), para una avenida máxima de $6700 \mathrm{~m}^{3} / \mathrm{s}$, 


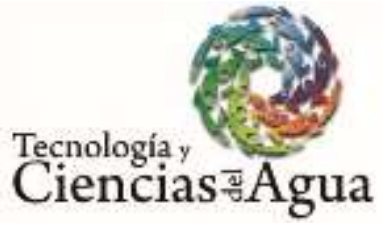

2022, Instituto Mexicano de Tecnología del Agua

Open Access bajo la licencia CC BY-NC-SA 4.0 (https://creativecommons.org/licenses/by-nc-sa/4.0/)

además de contar con un dique fusible de $10 \mathrm{~m}$ y un canal por margen derecha. En 1990 (del 11 al 22 de agosto), durante la construcción se presentó una avenida de $5300 \mathrm{~m}^{3} / \mathrm{s}$, lo que provocó un aumento en el embalse (102.60 msnm). En 1992 (del 16 al 20 de enero), se tuvo nuevamente una avenida de $10800 \mathrm{~m}^{3} / \mathrm{s}$ de gasto instantáneo y un gasto máximo diario de $9334 \mathrm{~m}^{3} / \mathrm{s}$, que provocó un aumento en el nivel del embalse de la cota de $70 \mathrm{msnm}$ a la cota de $108 \mathrm{msnm}$, lo que hizo rebasar la ataguía aguas arriba. Se tuvo que abrir el dique fusible y se comenzó a inundar entre la ataguía y la cortina para evitar un daño mayor y el colapso de la estructura. Se llegó a la cota máxima de 123.60 msnm, apenas por debajo de la cara de la cortina. Posteriormente se tuvo una segunda avenida de $7700 \mathrm{~m}^{3} / \mathrm{s}$, alcanzando la cota de $112.40 \mathrm{msnm}$, llenando de nuevo el recinto entre la ataguía y la cortina, lo que provocó una deformación en la ataguía y retraso en el programa de construcción de la estructura.

Lo anterior dejó las siguientes lecciones y experiencias en cuanto a las obras de desvío: 1) la importancia de colocar un dique fusible para salvaguardar la integridad de la ataguía ; 2 ) la ventaja de colocar concreto hidráulico tan sólo en la plantilla de los túneles permitió pasar de 164 a 188 años en periodo de retorno ( $T r$ ), asimismo, al cambiar a concreto lanzado en las paredes y bóveda permite pasar a un $\operatorname{Tr}$ de 313 años, que representa un aumento significativo en la seguridad del sistema hidráulico, geológico y estructural, lo que también permite conseguir ahorros significativos en las obras de desvío. Derivado de lo anterior nace 
2022, Instituto Mexicano de Tecnología del Agua

Open Access bajo la licencia CC BY-NC-SA 4.0

(https://creativecommons.org/licenses/by-nc-sa/4.0/)

el concepto de "rugosidad compuesta", que puede implementarse con un análisis de riesgo para cada caso de diseño de obras de desvío.

\section{Aspectos generales de rugosidad compuesta en túneles o canales}

Sea un canal o túnel cuya sección transversal consiste en subsecciones de diferentes formas (circular, trapecial, arco, herradura, etc.), para el caso de la rugosidad compuesta el factor principal es el coeficiente de resistencia $n$, el cual puede ser combinado en plantillas, paredes y bóveda. Este coeficiente modifica la distribución de velocidad a lo largo de la sección transversal (Marengo, 2019). Para su estudio existen diversas ecuaciones que permiten definir su valor de forma homogénea considerando sólo el perímetro mojado (Marengo \& Arreguín, 2008). El estudio de los efectos de la variación de la rugosidad en el flujo ha sido estimado por diversos análisis: mediante modelos físicos, numéricos, bidimensionales, 2D y tridimensionales, al igual que con la instrumentación en sitio combinado con los análisis numéricos teóricos y empíricos, objeto de estudio de la presente investigación. 


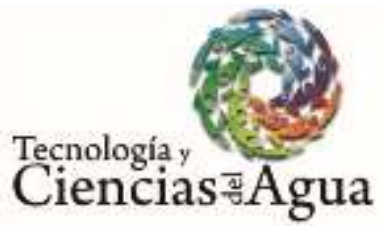

2022, Instituto Mexicano de Tecnología del Agua

Open Access bajo la licencia CC BY-NC-SA 4.0 (https://creativecommons.org/licenses/by-nc-sa/4.0/)

La resistencia al flujo depende de cuatro componentes de acuerdo con Rouse (1965): 1) la capa de fricción, 2) el arrastre, 3) la resistencia de deformación y 4) la resistencia asociada con la inestabilidad del flujo. Ecoeficiente de resistencia $f$ de Weisbach está en función $(F)$ de:

$f=F(\boldsymbol{R e}, k, \eta, N, F, U)$

Donde $\boldsymbol{R} \boldsymbol{e}$ es el número de Reynolds; $k$, la rugosidad relativa, que se expresa como $k s / R h k$, donde $k s$ es el equivalente a la rugosidad de la superficie de la pared y $R h$ es el radio hidráulico del flujo; $\eta$, función de la forma geométrica de la sección transversal; $N$, el número de uniformidad del canal tanto en el contorno como en el plano; $F$, el número de Froude, y $U$ es el grado de inestabilidad del flujo. Rouse (1965) demostró que el diagrama de Moody es un caso especial de la Ecuación (1) para flujo constante en tuberías rectas rígidas de diámetro constante al sólo considerar dos de los seis parámetros independientes, que son: el número de Reynolds y la rugosidad relativa $k s / \boldsymbol{R} \boldsymbol{e}$; este último permite calcular la rugosidad de Nikuradse.

Las fórmulas usadas por lo común en canales abiertos con flujo uniforme para calcular el coeficiente de resistencia son:

Ecuación de Manning: 
$V=\frac{K_{n}}{n} R h^{2 / 3} S_{f}^{1 / 2}$

Ecuación homogénea de Manning:

$V=\frac{g^{1 / 2}}{n_{g}} R h^{2 / 3} S_{f}^{1 / 2}$

Ecuación de Darcy-Weisbach:

$V=\left(\frac{2 g}{f}\right)^{1 / 2} D^{1 / 2}\left(\frac{h_{f}}{L}\right)^{1 / 2}$

Ecuación de Chézy:

$V=C R_{h}^{1 / 2} S_{f}^{1 / 2}$

Ecuación de Hazen-Williams: 
Tecnologíay

Ciencias $\approx$ Agua
2022, Instituto Mexicano de Tecnología del Agua

Open Access bajo la licencia CC BY-NC-SA 4.0 (https://creativecommons.org/licenses/by-nc-sa/4.0/)

$V=K_{H W} C_{H W} R^{0.63} S_{f}^{0.54}$

Donde $V$ es la velocidad media de la sección transversal; $n, f$ y $C$, los coeficientes de resistencia de Manning, Weisbach y Chézy, respectivamente; $R_{h}$, el radio hidráulico; $S_{f}$, la pendiente de fricción; $g$, la aceleración de la gravedad, y $K_{n}=1 \mathrm{~m}^{1 / 2} / \mathrm{s}$.

Los coeficientes de resistencia se pueden relacionar utilizando las ecuaciones anteriores:

$\sqrt{\frac{8}{f}}=\frac{C}{\sqrt{g}}=\frac{K_{n}}{\sqrt{g}} \frac{R h^{1 / 6}}{n} \frac{R h^{1 / 6}}{n_{g}}=\frac{V}{\sqrt{g R h S_{f}}}$

De acuerdo con Marengo (2019), en la práctica profesional se sigue empleando la ecuación de Manning, que en el caso de un flujo uniforme y desde el punto de vista espacial (Chow, 1959) está definido como aquel en el que el tirante, el área hidráulica, la velocidad y la descarga en cada sección del túnel son constantes, y en que la pendiente de energía $S_{f}$, la de la superficie del agua $S_{w}$ y el del fondo del canal $S_{0}$ son paralelos, es decir: $S_{w}=S_{f}=S_{0}$. El denominador se llama velocidad cortante $\left(V_{*}\right)$, que se define como: 
2022, Instituto Mexicano de Tecnología del Agua

Open Access bajo la licencia CC BY-NC-SA 4.0 (https://creativecommons.org/licenses/by-nc-sa/4.0/)

$V_{*}=\sqrt{g R h S_{f}}$

El cual permite determinar el coeficiente de fricción $C_{f}$ :

$C_{f}=\left(\frac{V_{*}}{V}\right)^{2}$

De acuerdo con la Ecuación (9) y la Ecuación (7), se puede expresar lo siguiente:

$C_{f}=\frac{f}{8}=\frac{g}{c^{2}}=\frac{g}{k_{n}^{2}} \frac{n^{2}}{R_{h}^{1 / 3}}=\frac{n_{g}^{2}}{R_{h}^{1 / 3}}$

Cuando se consideran diversos materiales de rugosidad, por ejemplo concreto hidráulico en la plantilla y paredes, y concreto lanzado en bóveda o roca, el valor de $n$ de la Ecuación (2) es recomendable estimar un coeficiente representativo de las rugosidades al que se le denominará en adelante "coeficiente de rugosidad equivalente", que además cambiará en función del tirante hidráulico (Marengo, 2019). 


\section{Diseño experimental}

\section{Instrumentación para la medición de variables hidráulicas}

\section{Características geométricas e hidráulicas de los túneles}

La investigación está centrada en el caso de estudio de los túneles de comunicación del vaso superior e inferior del río Grijalva, aguas arriba de la C.H. Peñitas (Ángel Albino Corzo), cuyas características se mencionan a continuación.

Consiste en dos túneles ( $\mathrm{T} 1$ y T2) ubicados en margen izquierda del río Grijalva, de sección portal de $14 \mathrm{~m}$ de ancho por $14 \mathrm{~m}$ de altura, y plantilla horizontal de concreto hidráulico y paredes y bóveda de concreto lanzado (Tabla 1), los cuales contribuyen a la regulación de la operación entre las dos centrales Malpaso y Peñitas (Tabla 2). 
Tecnología y

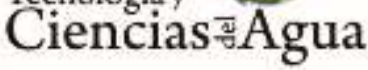

2022, Instituto Mexicano de Tecnología del Agua

Open Access bajo la licencia CC BY-NC-SA 4.0 (https://creativecommons.org/licenses/by-nc-sa/4.0/)

Tabla 1. Características geométricas de los túneles.

\section{Túnel 1 y 2}

\begin{tabular}{|c|c|c|}
\hline Gasto de diseño & 2604.00 & $\mathrm{~m}^{3} / \mathrm{s}$ \\
\hline Periodo de retorno & 10000 & años \\
\hline Nivel del embalse & 105.99 & $\mathrm{~m}$ \\
\hline Longitud túnel 1 & 1200.96 & $\mathrm{~m}$ \\
\hline Longitud túnel 2 & 1187.04 & $\mathrm{~m}$ \\
\hline Pendiente & Horizontal & $\mathrm{m}$ \\
\hline Canal de Ilamada y salida \\
comunes, elev & 76.50 & $\mathrm{~m}$ \\
\hline Sección portal & & $\mathrm{m}$ \\
\hline Radio bóveda & 7.00 & \\
\hline
\end{tabular}

Tabla 2. Niveles de operación de la C.H. Peñitas y la C.H. Malpaso.

\begin{tabular}{|l|c|}
\hline \multicolumn{2}{|c|}{ Presa Peñitas } \\
\hline Elevación NAME & $95.50 \mathrm{~m}$ \\
\hline Elevación NAMO & $87.40 \mathrm{~m}$ \\
\hline Elevación NAMINO & $85.00 \mathrm{~m}$ \\
\hline
\end{tabular}


2022, Instituto Mexicano de Tecnología del Agua

Open Access bajo la licencia CC BY-NC-SA 4.0 (https://creativecommons.org/licenses/by-nc-sa/4.0/)

\begin{tabular}{|l|c|}
\hline $\begin{array}{l}\text { Elevación labio superior compuertas del } \\
\text { vertedor }\end{array}$ & $91.14 \mathrm{~m}$ \\
\hline Unidades de generación & 4.00 \\
\hline Gasto por unidad & $349.00 \mathrm{~m}^{3} / \mathrm{s}$ \\
\hline \multicolumn{1}{|c|}{ Presa Malpaso } \\
\hline Elevación media desfogue obra de toma & $86.50 \mathrm{~m}$ \\
\hline Unidades de generación & 6.00 \\
\hline Gasto por unidad & $240.00 \mathrm{~m}^{3} / \mathrm{s}$ \\
\hline
\end{tabular}

\section{Instalación de la instrumentación}

Se realizó un proyecto de instrumentación hidráulica que consistió en la instalación de 53 sensores o celdas de medición de presión hidrostática, programadas para medir niveles hidráulicos, de los cuales 24 corresponden a cada túnel y separadas $50 \mathrm{~m}$ cada una (en cada túnel), así como cinco adicionales a lo largo de cada uno de los portales de entrada y salida (Figura 2). 
Tecnologíay

Ciencias ฐ A gua
2022, Instituto Mexicano de Tecnología del Agua

Open Access bajo la licencia CC BY-NC-SA 4.0 (https://creativecommons.org/licenses/by-nc-sa/4.0/)

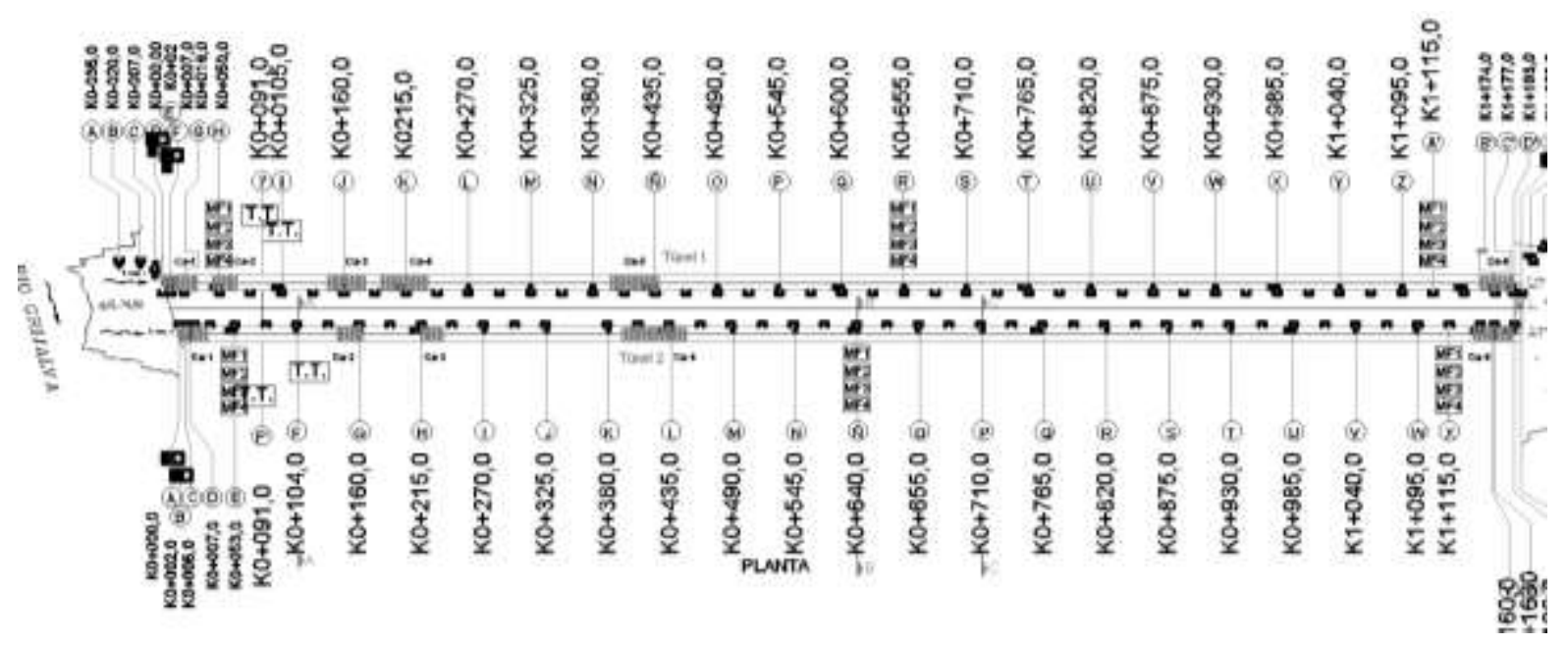

Figura 2. Localización de celdas en los túneles (túnel 1 superior y túnel 2 inferior en la figura).

Las celdas de presión o cells (en inglés), o sensores de presión, son de tipo "cuerda vibrante", las cuales quedaron instaladas dentro del concreto en la parte cóncava que une la pared con la plantilla en la sección transversal del túnel; a esa zona se le conoce como "chaflán" (Figura 3). Los sensores contienen un cable o hilo vibrante que detecta la presión hidráulica por medio de un diafragma que transforma la frecuencia de resonancia a un valor de presión hidráulica y por lo tanto a un valor de nivel hidráulico. Los sensores se calibran previamente en laboratorio y se realiza la programación en el sistema SCADA para transformarlos a valores de tirantes hidráulicos o de niveles hidráulicos en msnm. 


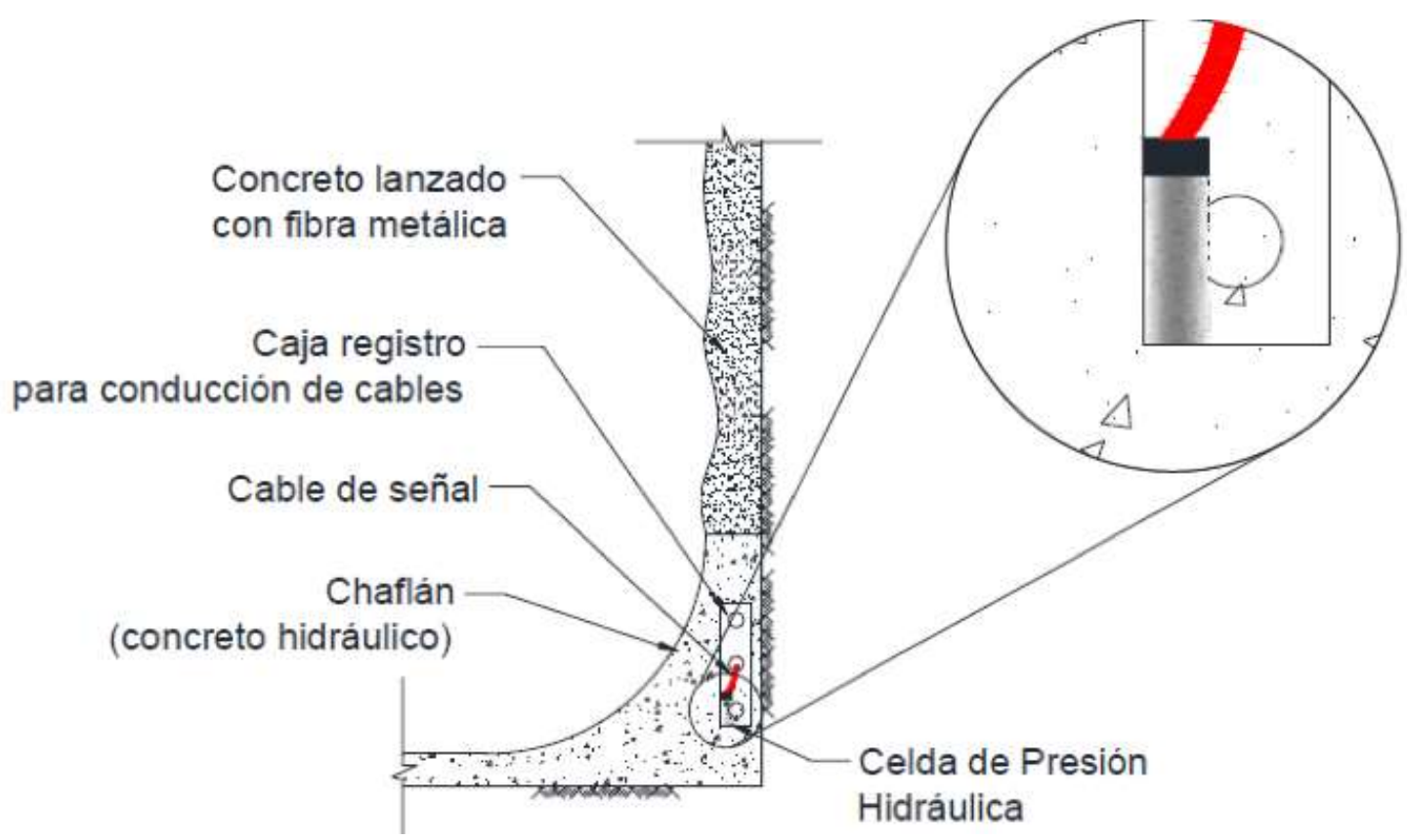

Figura 3. Colocación de celdas dentro del "chaflán".

Para el gasto o caudal se instaló un módulo de equipos doppler por cada túnel de tipo "tiempo en travesía (T.T.)" en las paredes. Cada módulo está localizado entre el cadenamiento 0+091 y el 0+105 (Figura 4); ello permitió que no se tuviera influencia por el efecto local de la entrada. El módulo consiste en cuatro pares (ocho sensores) de medición a diferentes alturas: a 2.5, 5, 6.5 y $8 \mathrm{~m}$ (Figura 5). Funciona para un rango de velocidades de $\pm 20 \mathrm{~m} / \mathrm{s}$ para canales con un ancho desde 0.75 $\mathrm{m}$ hasta $100 \mathrm{~m}$, y temperaturas máximas y mínimas desde $-20{ }^{\circ} \mathrm{C}$ hasta $+70{ }^{\circ} \mathrm{C}$, con una variación de la precisión de sólo un $0.5 \%$. 
Tecnologíay

Ciencias $\bar{v}$ Agua
2022, Instituto Mexicano de Tecnología del Agua

Open Access bajo la licencia CC BY-NC-SA 4.0 (https://creativecommons.org/licenses/by-nc-sa/4.0/)

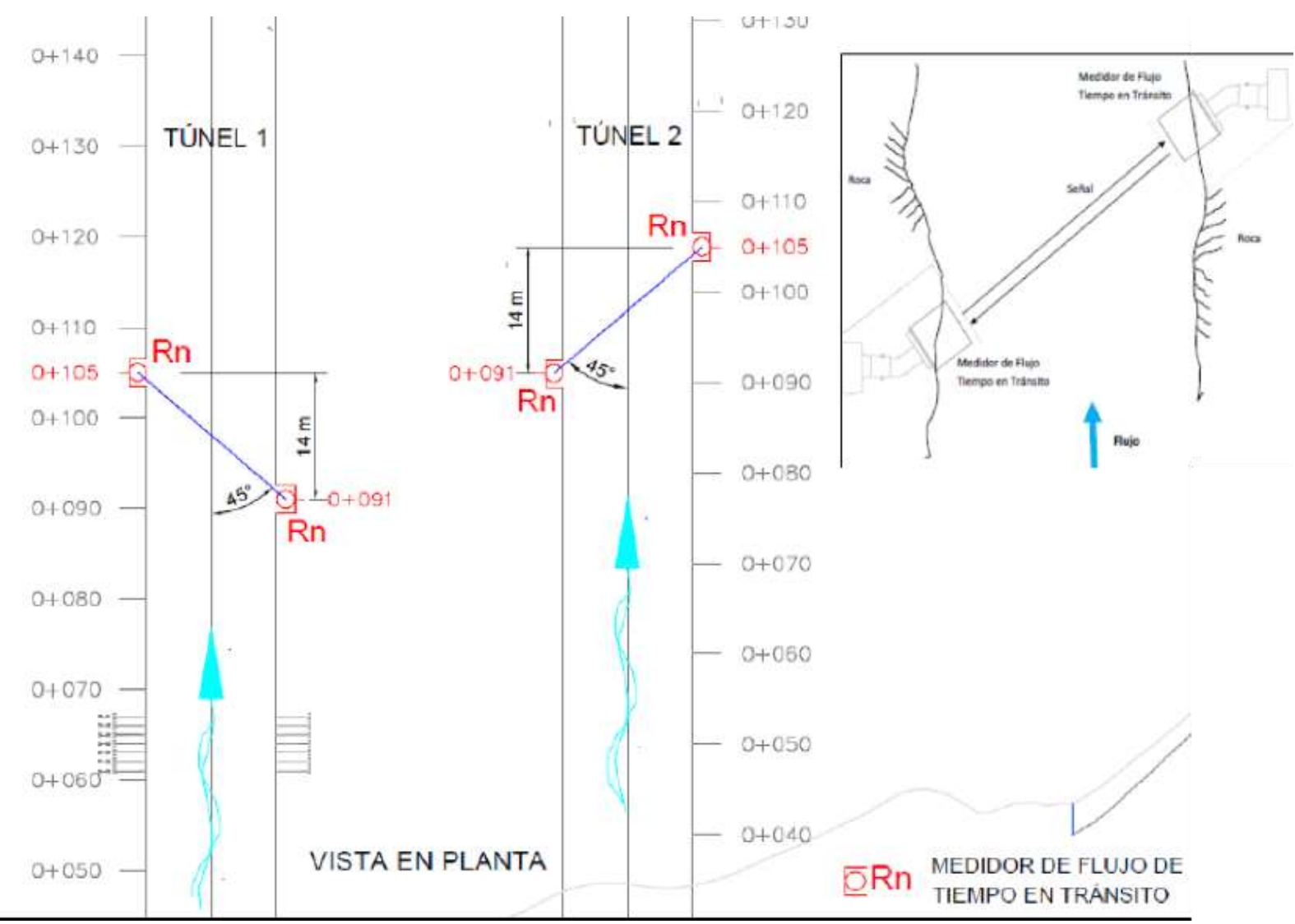

Figura 4. Ubicación de medidores "tiempo en travesía" (en planta). 


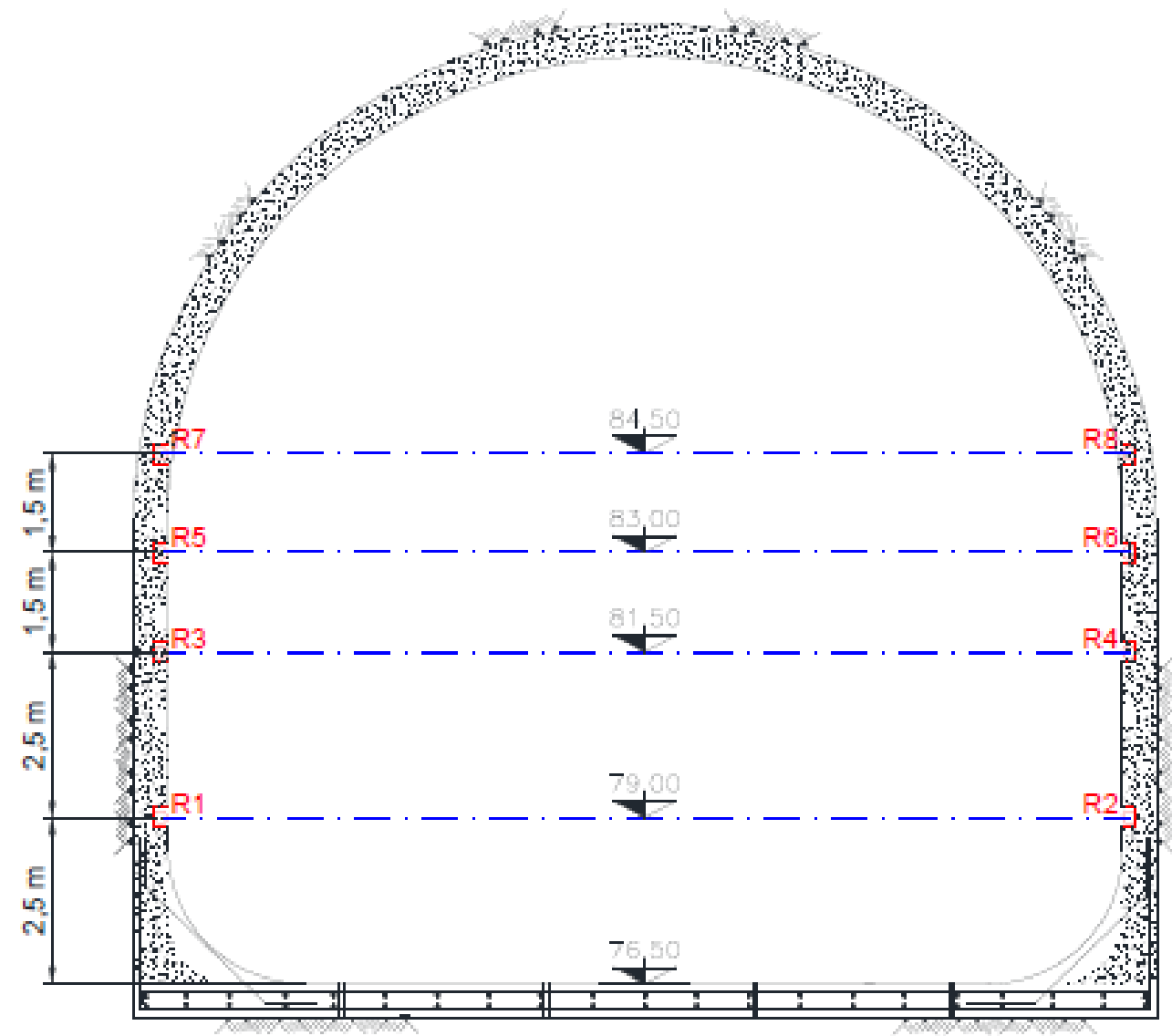

Figura 5. Ubicación de medidores "tiempo en travesía" (en perfil o sección).

El concepto de T.T. se debe a que el equipo envía un haz sonoro a otro instrumento instalado a 45 grados y a la misma elevación en la pared opuesta, midiendo en cada par el tiempo que éste tarda en regresar de aguas abajo hacia aguas arriba, con lo que se calcula la velocidad del fluido. Dado que conducen agua con una cantidad muy pequeña de 
Tecnología y

Ciencias $\sqrt{\mathrm{v}} \mathrm{Agua}$
2022, Instituto Mexicano de Tecnología del Agua

Open Access bajo la licencia CC BY-NC-SA 4.0 (https://creativecommons.org/licenses/by-nc-sa/4.0/)

partículas en condiciones normales se favorece el funcionamiento de los medidores T.T.

Para la medición de velocidades cercanas a la pared se instalaron cuatro equipos también tipo doppler, pero de frecuencia mayor (3000 $\mathrm{kHz}$ ), lo que les permite medir velocidades a partir de 0.1 a $5.0 \mathrm{~m}$ desde la pared. Cada equipo tiene dos sensores a $25^{\circ}$, que le brinda redundancia a la medición. Se colocaron en tres secciones por túnel: K0+050, K0+655 y K1+115 (Figura 6), así como a diferentes alturas: $2.5,5,6.5$ y $8 \mathrm{~m}$ (Figura 7), para medir un espectro general en la sección. Su configuración quedó programada para medir a partir de $10 \mathrm{~cm}$ de la pared y hasta 1.5 $\mathrm{m}$ de distancia, pues el objetivo era medir en la zona de influencia de la pared. Este equipo tiene una variación en la precisión de sólo $0.1 \%$; mide en profundidades de hasta $30 \mathrm{~m}$ y sus rangos de velocidad son de \pm 6 $\mathrm{m} / \mathrm{s}$.

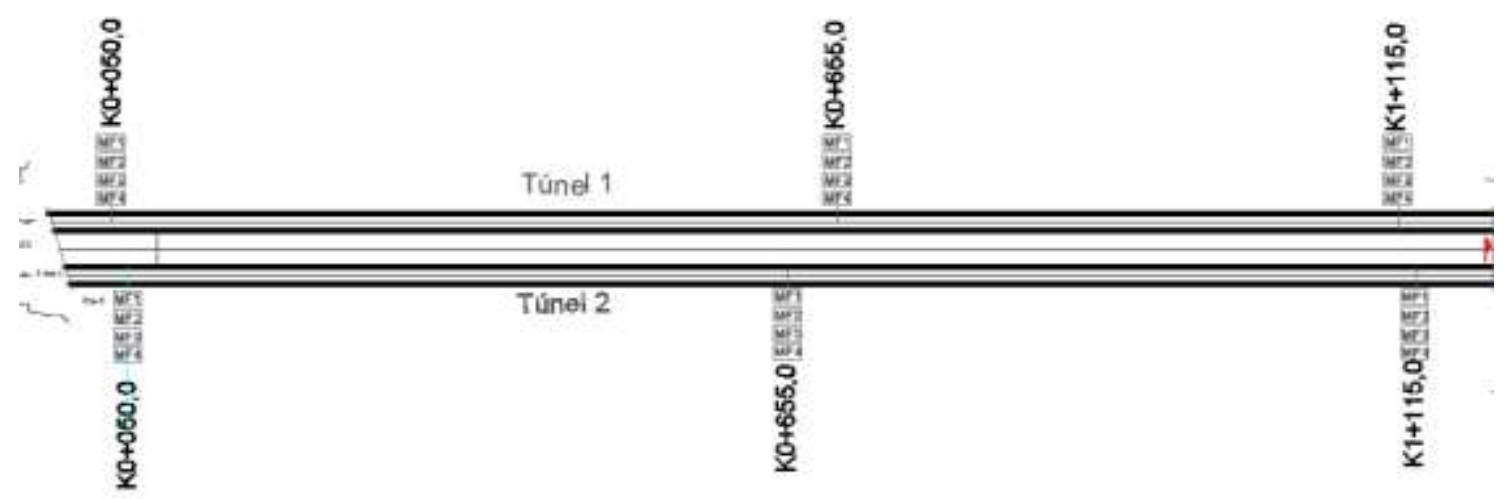

Figura 6. Ubicación de medidores de velocidad doppler (en planta). 


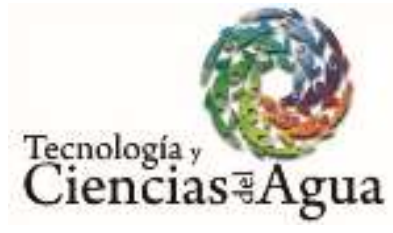

2022, Instituto Mexicano de Tecnología del Agua

Open Access bajo la licencia CC BY-NC-SA 4.0

(https://creativecommons.org/licenses/by-nc-sa/4.0/)

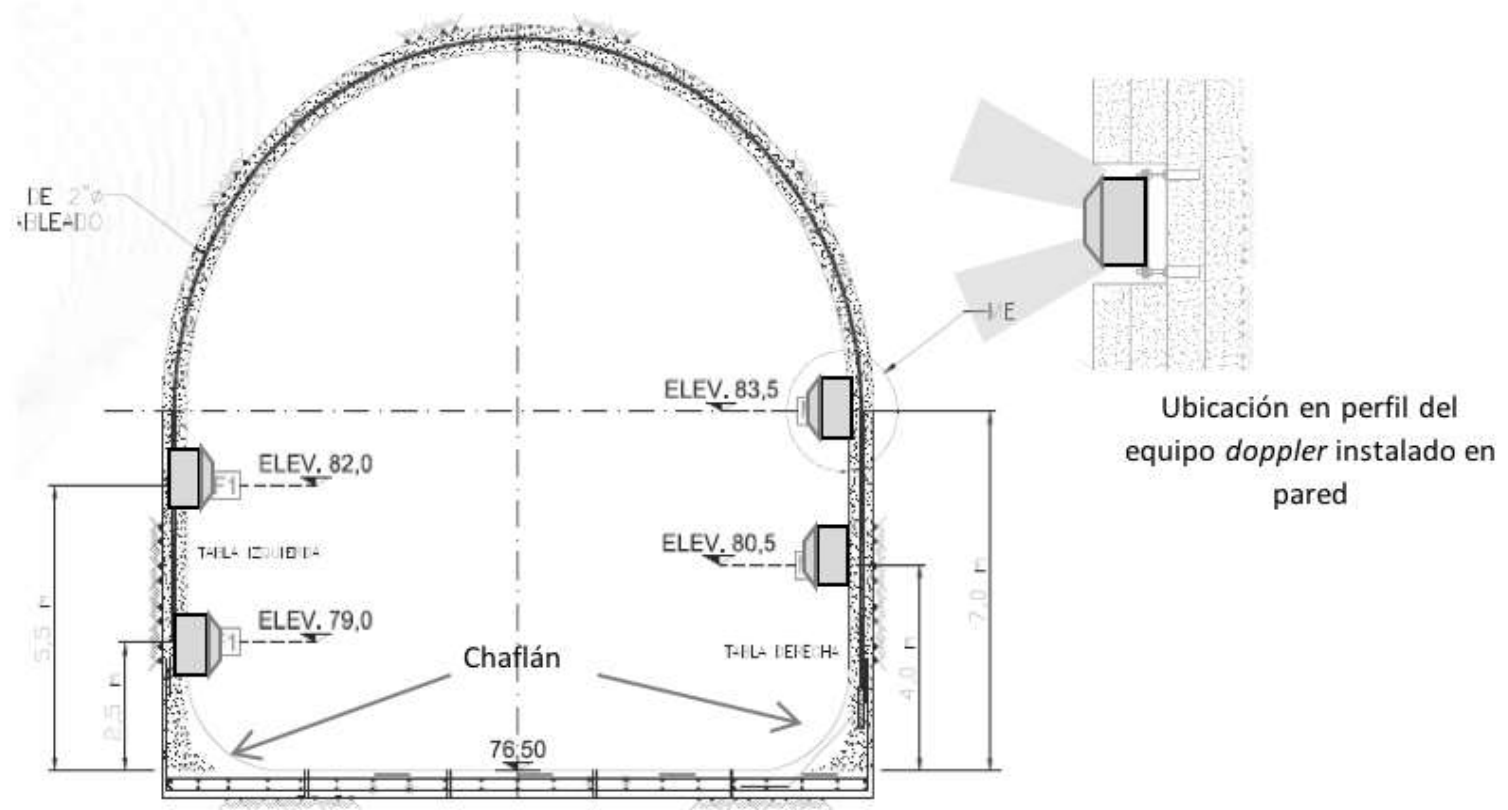

Figura 7. Ubicación de medidores de velocidad doppler (en sección).

\section{Campaña de aforo en el portal de entrada}

Con el propósito de verificar la certidumbre en las variables hidráulicas se realizó una campaña de aforo en el canal de llamada de los portales de entrada a los túneles (Figura 1), y se comparó con el gasto de los 
2022, Instituto Mexicano de Tecnología del Agua

Open Access bajo la licencia CC BY-NC-SA 4.0

(https://creativecommons.org/licenses/by-nc-sa/4.0/)

medidores tipo T.T. instalados dentro del túnel. En el aforo se utilizó un perfilador acústico movible doppler (ADCP) con las siguientes características: profundidad de $75 \mathrm{~cm}$ a $30 \mathrm{~m}$; variación de la precisión de $0.5 \%$; velocidades $\pm 20 \mathrm{~m} / \mathrm{s}$; y temperaturas máximas y mínimas de $-5{ }^{\circ} \mathrm{C} \mathrm{a}+45^{\circ} \mathrm{C}$.

Se obtuvieron aproximaciones de caudal del doppler movible ADCP con respecto al medidor T.T. del -3 al $8 \%$; dicha diferencia es aceptable sumando las tolerancias de ambos equipos. Se concluye que el medidor tipo T.T. instalado dentro de los túneles da una mejor calidad de medición instantánea en cada lectura: su configuración está diseñada para ajustarse con los otros pares de medidores en caso de llegar a faltar alguno; cuenta con un $0.5 \%$ de margen de error absoluto, y sus parámetros hidráulicos obedecen a las teorías y leyes fundamentales de la mecánica de fluidos con aplicación a la distribución de velocidades en un canal con fondo rugoso.

\section{Metodología}




\section{Primera parte. Planteamiento teórico para el cálculo de la rugosidad compuesta de Manning, $n_{c}$}

Una vez verificada la calidad de los datos de medición de gasto y velocidad se procede con el planteamiento teórico para el cálculo de la rugosidad compuesta $n_{c}$, partiendo de la ecuación de Bernoulli y la ecuación de Manning (Sotelo, 2002), donde se conocen todas las variables excepto la rugosidad (Figura 8 ). 


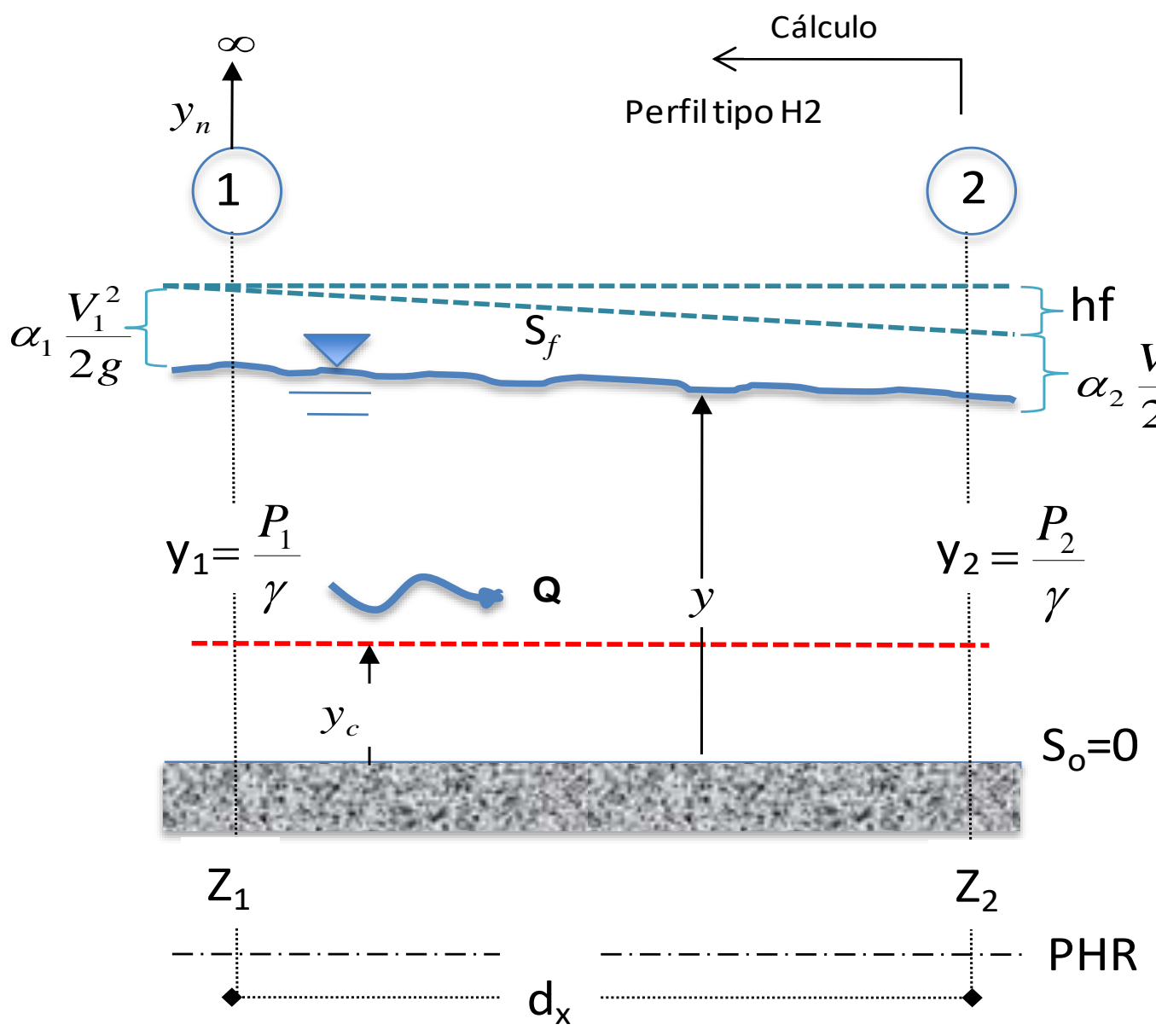

Figura 8. Planteamiento del cálculo hidráulico para estimar la rugosidad.

Si sólo desconocemos las pérdidas por fricción, $h_{f}$ : 


$$
h_{f}=\int_{1}^{2} S_{f} d x=\int_{1}^{2} \frac{Q^{2} n_{c}{ }^{2}}{A^{2} R_{h}{ }^{4 / 3}} d x \approx \frac{\Delta x}{2} n_{c}{ }^{2} Q^{2}\left(\frac{1}{A_{1}^{2} R_{h_{1}}{ }^{4 / 3}}+\frac{1}{A_{2}^{2} R_{h_{2}}{ }^{4 / 3}}\right)
$$

Donde $S_{f}$ es la pendiente de fricción; $A$, el área hidráulica; $R_{h}$, el radio hidráulico; $k_{l}$, el coeficiente de pérdida local en caso de existir; $y_{1}-$ $y_{2}$ es la diferencia de tirantes en una sección, como se observa en la Figura 8, y $Q$, el gasto, es conocido. Despejando la rugosidad compuesta en la sección $n_{c}$ de la Ecuación (11) resulta:

$$
\left.n_{c}=\left[\frac{2\left(y_{1}-y_{2}\right)+\frac{Q^{2}}{g}\left(\frac{1}{A_{1}^{2}}-\frac{1}{A_{2}^{2}}-\frac{k_{l}}{A_{2}^{2}}\right)}{Q^{2} \Delta x\left(\frac{1}{A_{1}^{2} R h_{1}{ }^{4} / 3}+\frac{1}{A_{2}^{2} R h_{2}}{ }^{4 / 3}\right.}\right)\right]^{1 / 2}
$$

Donde:

$$
\Delta x=\left(x_{2}-x_{1}\right)
$$

La rugosidad está compuesta por concreto hidráulico en la plantilla y "chaflán", y concreto lanzado en paredes y bóveda (Figura 9). 


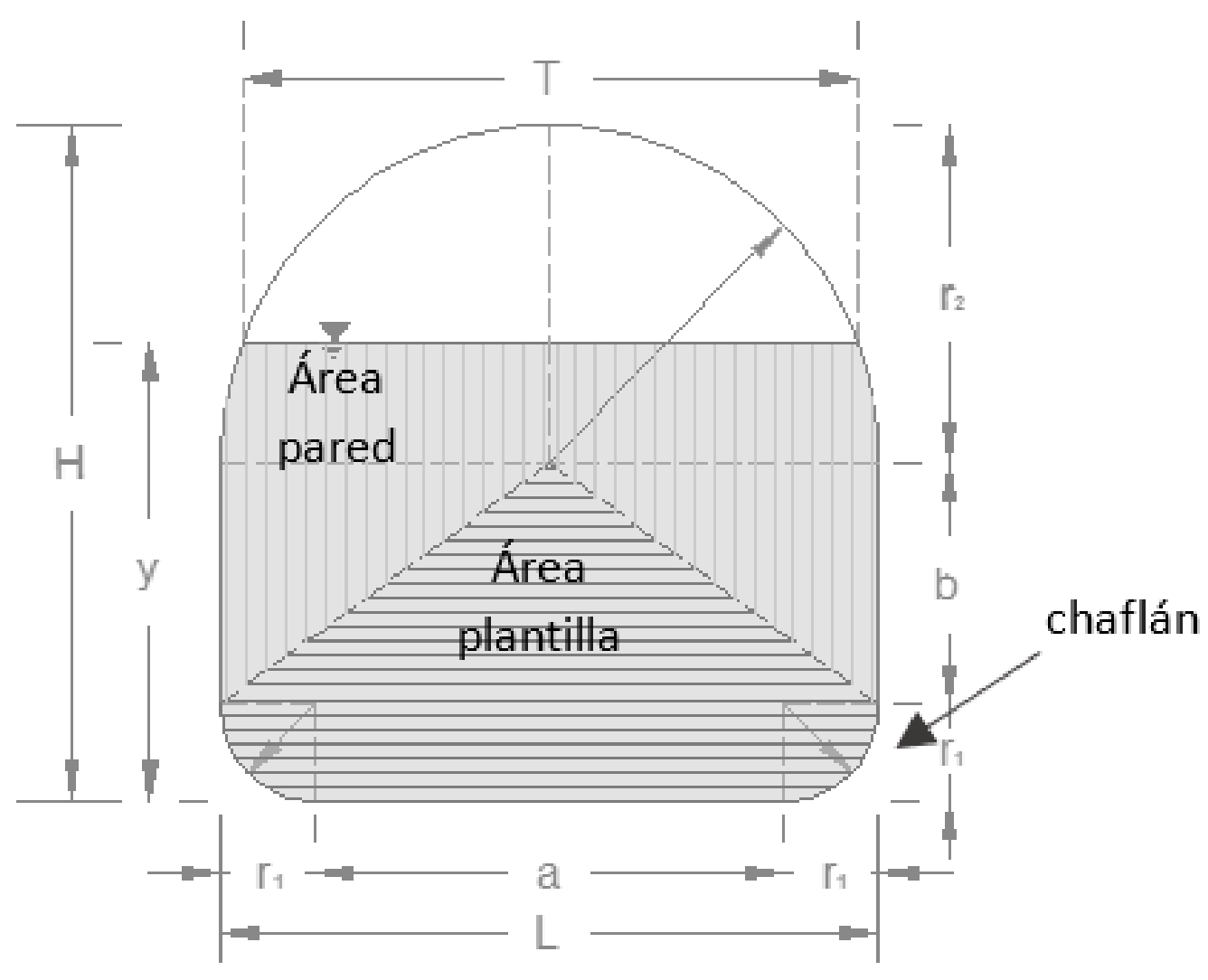

Figura 9. Sección portal con rugosidad compuesta.

Una vez obtenidos los valores de rugosidad $n_{c}$ por cada tramo se Ileva a cabo la discretización de la rugosidad equivalente $k_{s}$ de Nikuradse para obtener el valor de rugosidad real de pared y plantilla. 


\section{Segunda parte. Estimación de la rugosidad equivalente de Nikuradse}

\section{Ley logarítmica de velocidades de Prandtl y Von Kármán,}

La ley logarítmica desarrollada por Prandtl y Von Kármán establece que el perfil de velocidades cercano a la pared o en la zona de capa límite puede expresarse como sigue (Schlichting, 1979):

$\frac{\bar{v}}{v_{*}}=\frac{1}{\kappa} \ln \frac{y}{k_{s}}+B$

Donde $\bar{v}$ representa la velocidad longitudinal promediada en el sentido de Reynolds; $v_{*}$, la velocidad del fluido en la zona de influencia de la pared; $y$, la distancia a la pared; $\kappa=0.4$, la constante de Von-Kármán; $k_{S}$, la rugosidad equivalente de Nikuradse, y $B=8.5$ para canales de fondo rugoso. Por lo tanto, la Ecuación (4) para canales completamente rugosos queda: 
Tecnologíay

Ciencias $\approx$ Agua
2022, Instituto Mexicano de Tecnología del Agua

Open Access bajo la licencia CC BY-NC-SA 4.0 (https://creativecommons.org/licenses/by-nc-sa/4.0/)

$$
\frac{\bar{v}}{v_{*}}=2.5 \ln \frac{y}{k_{s}}+8.5
$$

Existen tres condiciones para determinar la constante $B$, que dependen del número de Reynolds, en términos de $v_{*} k_{s} / v$, donde es igual a cinco para paredes completamente lisas; de 5 a 70 corresponde a la transición de un régimen hidráulicamente liso a uno completamente rugoso; y mayor a 70 para flujo completamente rugoso (Schlichting, 1979) (Figura 10).

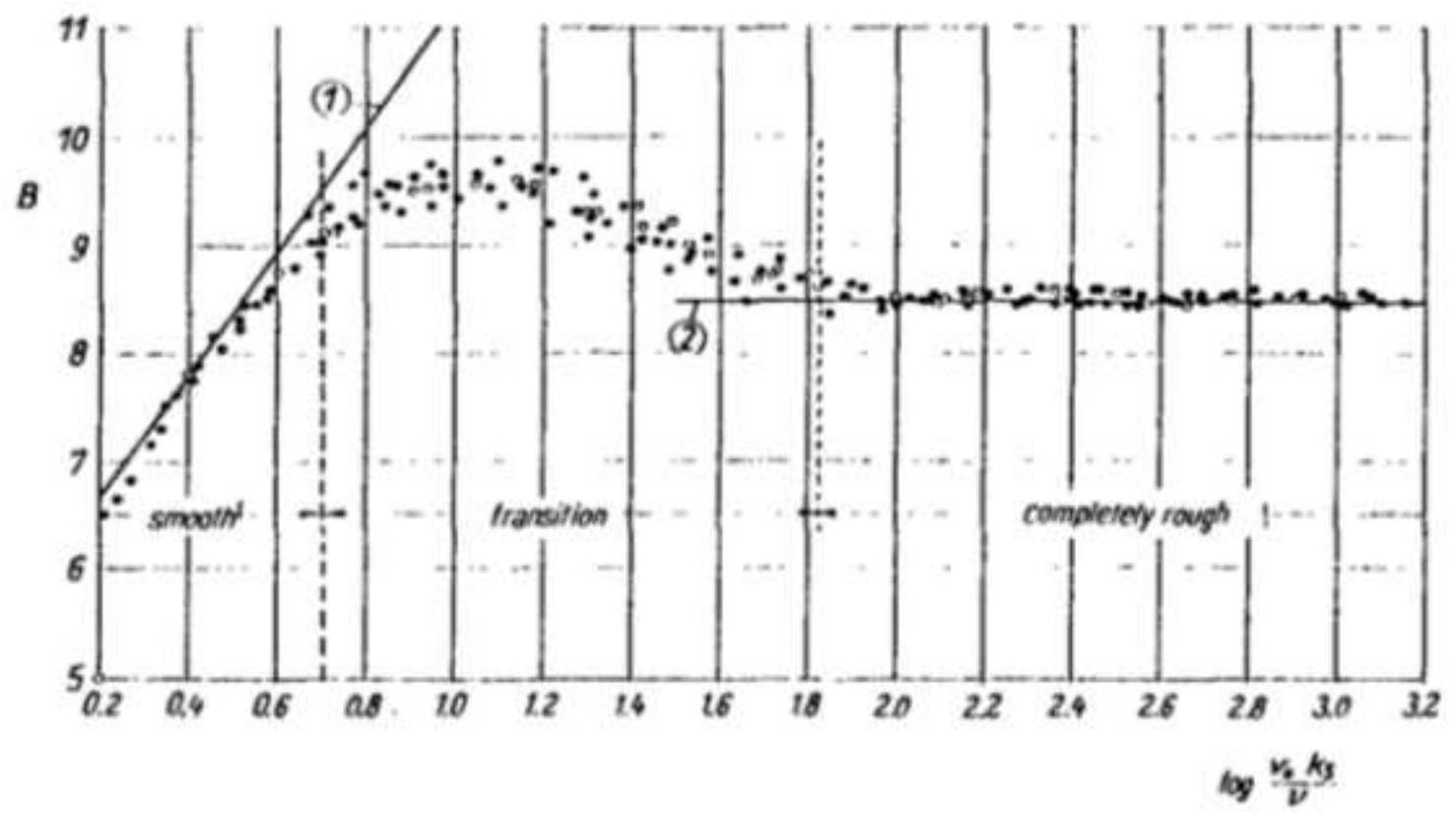


Figura 10. Función B para la rugosidad en términos de $v_{*} k_{s} / v$ para rugosidad de arena de Nikuradse (Schlichting, 1979).

\section{Capa límite y el espesor de desplazamiento}

La capa límite de un flujo es la zona en la que el movimiento del fluido experimenta de manera dominante el efecto de frenado que provoca la presencia de la pared en vista de la condición de frontera de no deslizamiento; este concepto se debe a Ludwig Prandtl.

También se puede describir como el espesor necesario que debe desplazarse la pared para que el volumen perdido se iguale con el volumen perdido por el efecto viscoso de la pared (Figura 11). El desplazamiento vertical referido se denomina "espesor de desplazamiento" y se define como:

$\delta^{*}=\int_{0}^{\delta}\left(1-\frac{\bar{v}}{v}\right) \mathrm{dy}$ 
Tecnología y

Ciencias $\sqrt{\mathrm{v}} \mathrm{Agua}$
2022, Instituto Mexicano de Tecnología del Agua

Open Access bajo la licencia CC BY-NC-SA 4.0 (https://creativecommons.org/licenses/by-nc-sa/4.0/)

Donde $\bar{v}$ es la velocidad longitudinal del flujo a una distancia de la superficie $y$ de la pared, medida en forma perpendicular a la pared, y $v$ es la velocidad fuera de la capa límite.

$h(\zeta)$

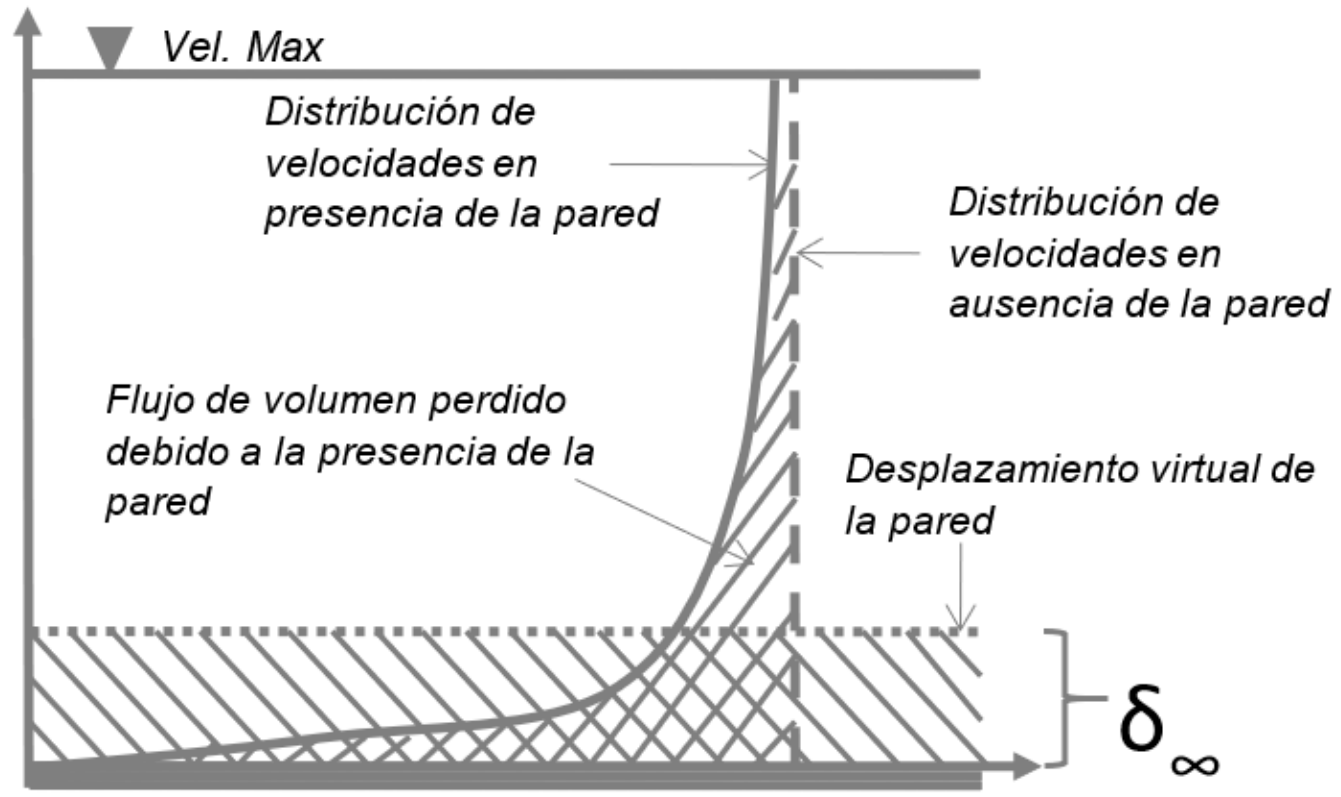

$V$

Figura 11. Interpretación del espesor de desplazamiento.

El valor del espesor de desplazamiento $\delta^{*}$ por lo general varía desde un décimo del espesor de la capa límite de acuerdo con la magnitud del número de Reynolds, donde pequeños rangos de viscosidad son grandes números de Reynolds. 


\section{Perfil de velocidades en la capa límite}

Con base en lo anterior se planteó la metodología experimental basada en los registros de los medidores de velocidad doppler para velocidades a partir de $10 \mathrm{~cm}$ de distancia de la pared y hasta $2.1 \mathrm{~m}$ y con distancias de medición a cada $20 \mathrm{~cm}$.

Primero se verifica si las velocidades registradas se encuentran dentro del espesor de desplazamiento $\left(\delta_{d}\right)$ a través de la siguiente ecuación:

$\delta d=\left\{1-\left[e^{-k B} \frac{k s}{h}+\frac{\ln \frac{h}{k s}+B k-1}{\ln \frac{h}{k s}+B k}\right]\right\} h$ 
Donde $\delta d$ es el espesor de desplazamiento; $\kappa=0.4$, la constante de Von-Kármán; $B=8.5$ para canales de fondo rugoso; $k_{s}$, la rugosidad equivalente de Nikuradse; y $h$ es el valor medio del tirante en la sección.

Cada velocidad registrada por el sensor doppler considera diversas distancias en la longitud del espesor de desplazamiento, eso genera diversos perfiles de velocidad a lo largo de la influencia de la capa límite y el espesor de desplazamiento. Para efectos de análisis se consideran aquellos valores que se desarrollan como curvas de velocidad logarítmica.

\section{Rugosidad equivalente de Nikuradse, $k s$}

Para obtener la rugosidad equivalente de Nikuradse, a partir de la Ecuación (5) de la ley logarítmica se despeja el parámetro $k_{s}$ :

$k_{S}=e^{\left(k B-\frac{\beta}{v_{*}}\right)}$

Donde: 
$\beta=\bar{v}_{2}-\left(\frac{\bar{v}_{2}-\bar{v}_{1}}{\eta_{2}-\eta_{1}}\right) \eta_{2}$

$\eta=\ln \zeta=\ln y$

Donde $\beta$ define el promedio de velocidades a partir de la primera lectura de medición, que va de 10 a $30 \mathrm{~cm}$ y posteriormente cada $20 \mathrm{~cm}$, es decir, $\bar{v}_{2}-\bar{v}_{1}$ se refiere al valor de velocidad obtenido con el sensor a $30 \mathrm{~cm}\left(\bar{v}_{2}\right)$ y a $10 \mathrm{~cm}\left(\bar{v}_{1}\right)$. Por otro lado, $\eta=\ln \zeta=\ln y$, donde $y$ es la distancia con respecto a la pared desde el sensor (a 10 y $30 \mathrm{~cm}$ ).

La velocidad en la región de la pared $\left(v_{*}\right)$ queda definida como:

$v_{*}=\alpha=\frac{\bar{v}_{2}-\bar{v}_{1}}{\eta_{2}-\eta_{1}}$

De esta manera, obtenida la rugosidad equivalente $k_{s}$ es posible calcular el valor del parámetro $f$, conocido como la $f$ de Nikuradse.

De acuerdo con Aldama y Ocón (2002), en flujo uniforme en canales $S_{f}=S$, por lo que se puede encontrar una relación entre las fórmulas de Manning y la de Darcy-Weisbach, y se puede obtener la siguiente 
expresión que relaciona el factor de rugosidad $(n)$ con el factor de fricción adimensional $(f)$ :

$n=(f / 8 g)^{1 / 2} R h^{1 / 6}$

Asimismo, en un fondo plano constituido por granos de arena, la rugosidad $n$ es proporcional al diámetro de éstos elevados a 1/6 (Aldama, \& Ocón, 2002), lo que resulta en la siguiente ecuación:

$n=k_{m} g^{-1 / 2} k s^{1 / 6}$

Donde $k_{m}$ es una constante adimensional igual a 0.129765776 (Aldama \& Ocón, 2002). Asimismo, considerando para canales anchos $R=$ $h$ y despejando $f$ se obtiene:

$f=8 k_{m}^{2}(k s / R h)^{1 / 3}$

De acuerdo con Aldama y Ocón (2002), las gráficas para el factor de fricción $f$ correspondiente a conductos circulares trabajando llenos o a la mitad, y a canales anchos producen valores que no exceden más del 5 
2022, Instituto Mexicano de Tecnología del Agua

Open Access bajo la licencia CC BY-NC-SA 4.0 (https://creativecommons.org/licenses/by-nc-sa/4.0/)

$\%$ de diferencia, por lo que se puede incluir la aplicabilidad de las ecuaciones anteriores.

Para el presente estudio se considera aplicar el procedimiento anterior, utilizando como valores de entrada de la rugosidad compuesta aquellos obtenidos a partir de la Ecuación (12) y para las secciones donde se localizan los medidores doppler (K0+050, K0+655 y K1+115). Asimismo, aquellos que se encuentren dentro de los intervalos de rugosidad de concreto hidráulico entre 0.012 y 0.019 , y lanzado entre 0.020 y 0.028 recomendados (Marengo \& Arreguín, 2008). También se consideran aquellos que se encuentren dentro del espesor de desplazamiento; esto es, se revisa el perfil de velocidades de cada uno de los registros, en donde sólo se eligen aquellos que se ajustan a la distribución logarítmica de velocidades en toda la longitud del espesor de desplazamiento.

\section{Tercera parte. Modelo teórico unidimensional y calibración de resultados con aplicación en 18 ecuaciones empíricas de rugosidad compuesta}


2022, Instituto Mexicano de Tecnología del Agua

Open Access bajo la licencia CC BY-NC-SA 4.0 (https://creativecommons.org/licenses/by-nc-sa/4.0/)

Una vez obtenidos los parámetros de rugosidad de pared (Ecuación (22)), y conocida la rugosidad compuesta mediante la ecuación de la Energía (Ecuación (12)) resta aplicar cada una de las 17 ecuaciones empíricas de rugosidad compuesta conocidas (Tabla 3 ), para obtener el parámetro de rugosidad que mejor se aproxime a las mediciones.

Tabla 3. Ecuaciones empíricas para estimar el coeficiente de resistencia $n_{c}$ en canales con rugosidad compuesta (Marengo \& Arreguín, 2008).

\begin{tabular}{|c|c|l|c|}
\hline & & \multicolumn{2}{|c|}{ Supuestos } \\
\hline Eqs & $\boldsymbol{n c}_{\boldsymbol{c}}$ & \multicolumn{1}{|c|}{ Concepto } & Ecuación \\
\hline A & $=\frac{\sum n_{i} A_{i}}{A}$ & $\begin{array}{l}\text { Suma de la componente } n \text { pesada } \\
\text { por la relación de áreas o la } \\
\text { velocidad al esfuerzo cortante total } \\
\text { es la suma pesada de la velocidad } \\
\text { al esfuerzo cortante de la subárea. }\end{array}$ & $\sqrt{g R S}=\sum\left(\frac{P_{i}}{P} \sqrt{g R_{i} S_{i}}\right)$ \\
\hline$B$ & $=\sqrt{\sum n_{i}^{2} \frac{A_{i}}{A}}$ & $\begin{array}{l}\text { La fuerza de resistencia total es } \\
\text { igual a la suma de las fuerzas de } \\
\text { resistencia de las subáreas; o, } n_{i} \\
\text { pesada por VAi }\end{array}$ & $\left(V_{i} / V\right)=\left(R_{i} / R\right)^{7 / 6}$ \\
\hline$C$ & $=\frac{A \gamma R S=\Sigma P_{i} \gamma R_{i} S_{i}}{\sum\left(A_{i} / n_{i}\right)}$ & $\begin{array}{l}\text { La descarga total es la suma de } \\
\text { las descargas de subáreas }\end{array}$ & $\left(V_{i} / V\right)=\left(R_{i} / R\right)^{2 / 3}$ \\
\hline$D$ & $=\left[\frac{\sum\left(n_{i}^{3 / 2} A_{i}\right)}{A}\right]^{2 / 3}$ & $\begin{array}{l}\text { Igual que la ecuación E de Horton } \\
\text { y Einstein, pero erróneamente } \\
\text { derivada }\end{array}$ & $\left(S_{i} / S\right)=\left(R / R_{i}\right)^{4 / 3}$ \\
\hline
\end{tabular}




\begin{tabular}{|c|c|c|c|}
\hline$E$ & $=\left[\frac{1}{P} \sum\left(n_{i}^{3 / 2} P_{i}\right)\right]^{2 / 3}$ & $\begin{array}{l}\text { Velocidad media de la sección } \\
\text { transversal total es igual a la } \\
\text { velocidad media de la subárea. }\end{array}$ & $\begin{array}{c}V=V_{i} \\
A=\Sigma A_{i} \\
S=S_{i}\end{array}$ \\
\hline$F$ & $=\frac{P}{\sum\left(P_{i} / n_{i}\right)}$ & $\begin{array}{l}\text { La descarga total es la suma de } \\
\text { las descargas de las subáreas. }\end{array}$ & $\begin{array}{c}Q=\Sigma Q_{i} \\
\left(S_{i} / S\right)=\left(R / R_{i}\right)^{10 / 3}\end{array}$ \\
\hline$G$ & $=\left[\frac{1}{P} \sum\left(n_{i}^{2} P_{i}\right)\right]^{1 / 2}$ & $\begin{array}{l}\text { La fuerza de resistencia total, F, es } \\
\text { la suma de las fuerzas de } \\
\text { resistencia de la subárea, } \Sigma F i\end{array}$ & $\begin{array}{l}P \gamma R S=\sum P_{i} \gamma R_{i} S_{i} \\
\left(V_{i} / V\right)=\left(R_{i} / R\right)^{1 / 6}\end{array}$ \\
\hline$H$ & $=\frac{\sum\left(n_{i} P_{i}\right)}{P}$ & $\begin{array}{l}\text { La velocidad cortante total es la } \\
\text { suma de la velocidad cortante de } \\
\text { la subárea; o la rugosidad } \\
\text { componente que contribuye es } \\
\text { proporcionalmente lineal al } \\
\text { perímetro mojado. }\end{array}$ & $\begin{array}{c}\sqrt{g R S}=\sum\left(\frac{P_{i}}{P} \sqrt{g R_{i} S_{i}}\right) \\
\left(V_{i} / V\right)=\left(R_{i} / R\right)^{1 / 6} \text { or } \\
n_{c} P=\sum\left(n_{i} P_{i}\right)\end{array}$ \\
\hline$I$ & $=\left[\frac{R^{1 / 3}}{P} \sum \frac{n_{i}^{2} P_{i}}{R_{i}^{1 / 3}}\right]^{1 / 2}$ & $\begin{array}{l}\text { La fuerza de resistencia total, } F \text {, es } \\
\text { la suma de fuerzas de resistencia } \\
\text { de la subárea, } \Sigma F i\end{array}$ & $\begin{array}{c}P \gamma R S=\sum P_{i} \gamma R_{i} S_{i} \\
\left(V_{i} / V\right)=1\end{array}$ \\
\hline$J$ & $=\left[\frac{\sum n_{i}^{2} P_{i} R_{i}^{2 / 3}}{P R^{2 / 3}}\right]^{1 / 2}$ & $\begin{array}{l}\text { La fuerza de resistencia total es } \\
\text { igual a la suma de las fuerzas de } \\
\text { resistencia de la subárea. }\end{array}$ & $\begin{array}{l}P \gamma R S=\sum P_{i} \gamma R_{i} S_{i} \\
\left(V_{i} / V\right)=\left(R_{i} / R\right)^{1 / 2}\end{array}$ \\
\hline$K$ & $=\frac{P R^{7 / 6}}{\sum \frac{P_{i}}{n_{i}} R_{i}^{7 / 6}}$ & $\begin{array}{l}\text { La descarga total es la suma de } \\
\text { las descargas de la subárea. }\end{array}$ & $\begin{array}{c}Q=V A=\Sigma\left(V_{i} A_{i}\right) \\
\left(S_{i} / S\right)=\left(R / R_{i}\right)\end{array}$ \\
\hline$L$ & $=\frac{P R^{5 / 3}}{\sum \frac{P_{i} R_{i}^{5 / 3}}{n_{i}}}$ & $\begin{array}{l}\text { La descarga total es la suma de la } \\
\text { descarga de las subáreas. }\end{array}$ & $\begin{array}{c}Q=V A=\Sigma\left(V_{i} A_{i}\right) \\
\left(S_{i} / S\right)=1 \\
R=A / P\end{array}$ \\
\hline
\end{tabular}


Tecnologíay

Ciencias $\approx$ Agua
2022, Instituto Mexicano de Tecnología del Agua

Open Access bajo la licencia CC BY-NC-SA 4.0 (https://creativecommons.org/licenses/by-nc-sa/4.0/)

\begin{tabular}{|c|c|c|c|}
\hline$M$ & $=\frac{\sum P_{i} R_{i}^{5 / 3}}{\sum \frac{P_{i} R_{i}^{5 / 3}}{n_{i}}}$ & $\begin{array}{l}\text { Igual que la ecuación } L \text {, pero con } \\
\text { la definición modificada de } R \text {. }\end{array}$ & $\begin{array}{c}Q=V A=\sum\left(V_{i} A_{i}\right) \\
\left(S_{i} / S\right)=1 \\
\boldsymbol{R} \mathrm{de} \\
\frac{P R^{5 / 3}}{\sum P_{i} R_{i}^{5 / 3}}=\frac{A R^{2 / 3}}{\sum A_{i} R_{i}^{2 / 3}}=1\end{array}$ \\
\hline$N$ & $=\frac{\sum\left(n_{i} P_{i} / R_{i}^{1 / 6}\right)}{P / R^{1 / 6}}$ & $\begin{array}{l}\text { La velocidad al esfuerzo total } \sqrt{\mathrm{gRS}} \\
\text { es la suma de las velocidades al } \\
\text { esfuerzo cortantes de la subárea. }\end{array}$ & $\begin{array}{c}\sqrt{g R S}=\sum\left(\frac{P_{i}}{P} \sqrt{g R_{i} S_{i}}\right) \\
\left(V_{i} / V\right)=1\end{array}$ \\
\hline 0 & $=\frac{\sum\left(n_{i} P_{i} R_{i}^{1 / 2}\right)}{P R^{1 / 2}}$ & $\begin{array}{l}\text { La velocidad al esfuerzo cortante } \\
\text { total es la suma de la velocidad al } \\
\text { esfuerzo cortante de la subárea. }\end{array}$ & $\begin{array}{c}\sqrt{g R S}=\sum\left(\frac{P_{i}}{P} \sqrt{g R_{i} S_{i}}\right) \\
\left(V_{i} / V\right)=\left(R_{i} / R\right)^{2 / 3}\end{array}$ \\
\hline$P$ & $=\frac{\sum\left(n_{i} P_{i} R_{i}^{1 / 3}\right)}{P R^{1 / 3}}$ & $\begin{array}{l}\text { La velocidad cortante total es la } \\
\text { suma de la velocidad cortante de } \\
\text { la subárea. }\end{array}$ & $\begin{array}{c}\sqrt{g R S}=\sum\left(\frac{P_{i}}{P} \sqrt{g R_{i} S_{i}}\right) \\
\left(V_{i} / V\right)=\left(R_{i} / R\right)^{1 / 2}\end{array}$ \\
\hline$Z$ & $=\exp \left[\frac{\sum P_{i} h_{i}^{3 / 2} \ln r}{\sum P_{i} h_{i}^{3 / 2}}\right.$ & $\begin{array}{l}\text { La distribución de la velocidad } \\
\text { logarítmica sobre la profundidad } h \\
\text { para el canal ancho. }\end{array}$ & $\begin{array}{c}S=S_{i}, Q=\sum Q_{i} \\
\frac{Q_{i}}{2.5 \sqrt{g S}}=h_{i}^{\frac{3}{2}} P_{i}\left[\ln \left(\frac{10.93 h_{i}}{k_{i}}\right)\right] \\
\frac{Q_{i}}{2.5 \sqrt{g S}}=\Sigma h_{i}^{3 / 2} P_{i}\left[\ln \left(\frac{1093 h_{i}}{k_{i}}\right)\right] \\
n=0.0342 k\end{array}$ \\
\hline
\end{tabular}

Esto se logra mediante un modelo teórico unidimensional que toma en cuenta dichas ecuaciones y calibra los registros. El modelo teórico unidimensional tiene como variable el coeficiente de rugosidad del concreto lanzado $n_{c l}$ y está planteado para el caso de un perfil horizontal 
tipo $\mathrm{H} 2$, es decir, donde la sección de control se encuentra aguas abajo, y la ecuación que lo resuelve es:

$$
F(y)=\underbrace{Z_{S}-Z_{S-1}+Y_{S}+\frac{Q^{2}}{A_{S}{ }^{2} 2 g}(1+k l)+\frac{Q^{2} n^{2}}{A_{S}{ }^{2} R h_{S}{ }^{\frac{4}{3}}} \cdot \frac{\Delta x}{2}}_{\text {conocido }(Y S)} \underbrace{=Y_{S-1}+\frac{Q^{2}}{A_{S-1}{ }^{2} 2 g}-\frac{Q^{2} n^{2}}{A_{S-1}{ }^{2} R h_{S-1}{ }^{4 / 3}} \cdot \frac{\Delta x}{2}}_{\text {desconocido }(Y S-1)}
$$

Se considera como un modelo casi permanente, ya que se analiza por gastos y registros puntuales, y se aplican las teorías para un flujo gradualmente variado.

El modelo parte de un valor conocido aguas abajo, que es el tirante medido por la celda. Teniendo el tirante existe una relación única para obtener las variables geométricas, como área, perímetro y radio hidráulico, las cuales previamente quedaron definidas mediante su fórmula correspondiente. Como variables se introducen el gasto, y la rugosidad de pared y plantilla obtenidas de las mediciones directas de los medidores doppler para cada caso. Este esquema se aplica a las 17 ecuaciones empíricas conocidas para estimar la rugosidad compuesta (Tabla 3). Lo anterior permite construir un perfil hidráulico que será ajustado con el perfil obtenido con los valores medidos de tirante mediante las celdas. 
Para seleccionar la mejor ecuación de ajuste se utiliza el concepto del mínimo error cuadrado (MEC), donde se comparan las rugosidades compuestas obtenidas en las secciones de medición de los equipos doppler a partir de la ecuación de Bernoulli y Manning (Ecuación (12)) con respecto a las rugosidades compuestas obtenidas con las 17 ecuaciones empíricas. En ambas se integraron las rugosidades puntuales de pared y de plantilla obtenidas con los equipos doppler (ecuaciones (18) a (24)). Con lo anterior, el MEC obtenido permitirá definir la ecuación de mejor ajuste entre las 17 conocidas o definir una nueva ecuación de ajuste.

\section{Resultados}

\section{Medición de variables hidráulicas}

Se programó la medición de niveles hidráulicos con las celdas de presión cada hora y se obtuvieron valores de 8.72 a $10.66 \mathrm{~m}$ de tirante. 
2022, Instituto Mexicano de Tecnología del Agua

Open Access bajo la licencia CC BY-NC-SA 4.0

(https://creativecommons.org/licenses/by-nc-sa/4.0/)

Las velocidades que se midieron con los equipos doppler a partir de $10 \mathrm{~cm}$ de la pared obtuvieron rangos de velocidad de 0.35 a $2.5 \mathrm{~m} / \mathrm{s}$. Sin embargo, dado que se tuvieron problemas de comunicación constante con los equipos de velocidad en el túnel 2 , sólo se consideró para el estudio de la rugosidad la información del túnel 1.

Los gastos por los equipos doppler "tiempo en travesía" para ambos túneles (QT1+QT2) en suma registraron desde 117 hasta $575 \mathrm{~m}^{3} / \mathrm{s}$ entre octubre de 2011 y febrero de 2012.

\section{Rugosidad compuesta a partir de las ecuaciones de Bernoulli y de Manning, Ecuación (1) y Ecuación (2)}

Los valores de rugosidad obtenidos para cada tramo de análisis se muestran en la Figura 12 y sólo se consideraron aquellos que se encontraban en los intervalos recomendados: concreto hidráulico entre 0.012 y 0.019 , y lanzado entre 0.020 y 0.028 recomendados (Marengo \& Arreguín, 2008). 
2022, Instituto Mexicano de Tecnología del Agua

Open Access bajo la licencia CC BY-NC-SA 4.0

(https://creativecommons.org/licenses/by-nc-sa/4.0/)

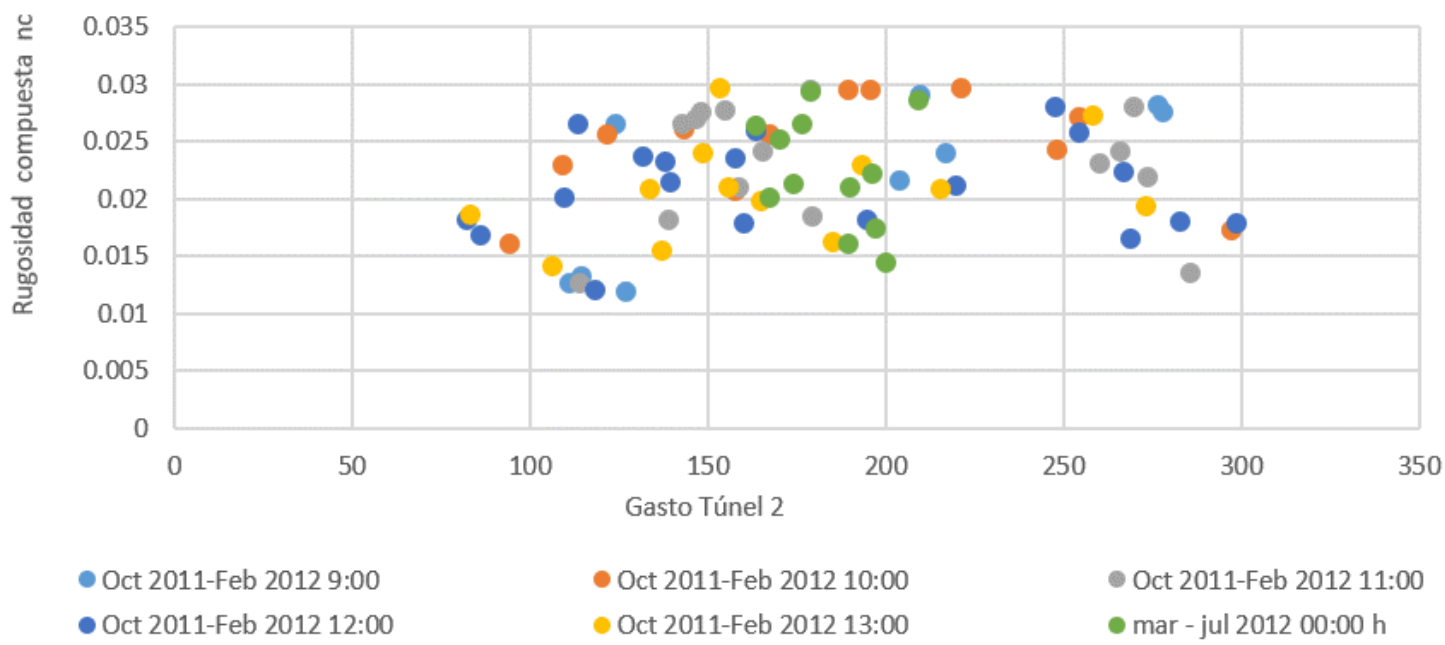

Figura 12. Valores de rugosidad compuesta obtenidos de la Ecuación (2) y dentro del intervalo recomendado (Marengo \& Arreguín, 2008).

\section{Rugosidad equivalente de Nikuradse $\left(k_{s}\right)$, Ecuación (8), y espesor de desplazamiento $(\delta d)$, Ecuación (7)}

Se modelaron las velocidades obtenidas de equipos doppler en las secciones $\mathrm{K} 0+050$ y $\mathrm{K} 1+115$. En el equipo localizado en el K0+655 no se pudo extraer información. Las mediciones estaban programadas cada hora desde octubre de 2011 hasta octubre de 2012. Cada sección contaba con cuatro equipos doppler (Figura 6 y Figura 7) y se programaron con 


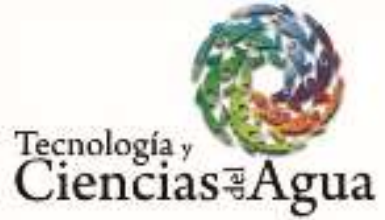

2022, Instituto Mexicano de Tecnología del Agua

Open Access bajo la licencia CC BY-NC-SA 4.0 (https://creativecommons.org/licenses/by-nc-sa/4.0/)

los demás equipos de medición: los equipos modulares para gasto y las celdas para la medición del tirante hidráulico.

Algunas complicaciones encontradas fueron que no siempre se tenía una medición constante de todos los equipos para todos los intervalos de tiempo. Asimismo, en la época de lluvias se tenían daños constantes en la transmisión por las sobrecargas que se presentaban en la caseta de instrumentación, donde se tenían los sistemas "SCADA", lo que llevó a hacer reparaciones continuas durante todo ese tiempo. Debido a que se perdió el seguimiento del mantenimiento de los equipos, ya no se pudo continuar con el análisis de los datos en los túneles para condiciones de gasto mayores.

Se obtuvieron más de 200 perfiles de velocidad para cada intervalo de medición desde 1 hasta 24 h en un año de medición.

Se seleccionaron aquellos registros que pertenecían a un perfil logarítmico, que sumaron más de 300 perfiles para caudales entre 117 y $575 \mathrm{~m}^{3} / \mathrm{s}$, como los que se muestran en la Figura 13, Figura 14 y Figura 15. 


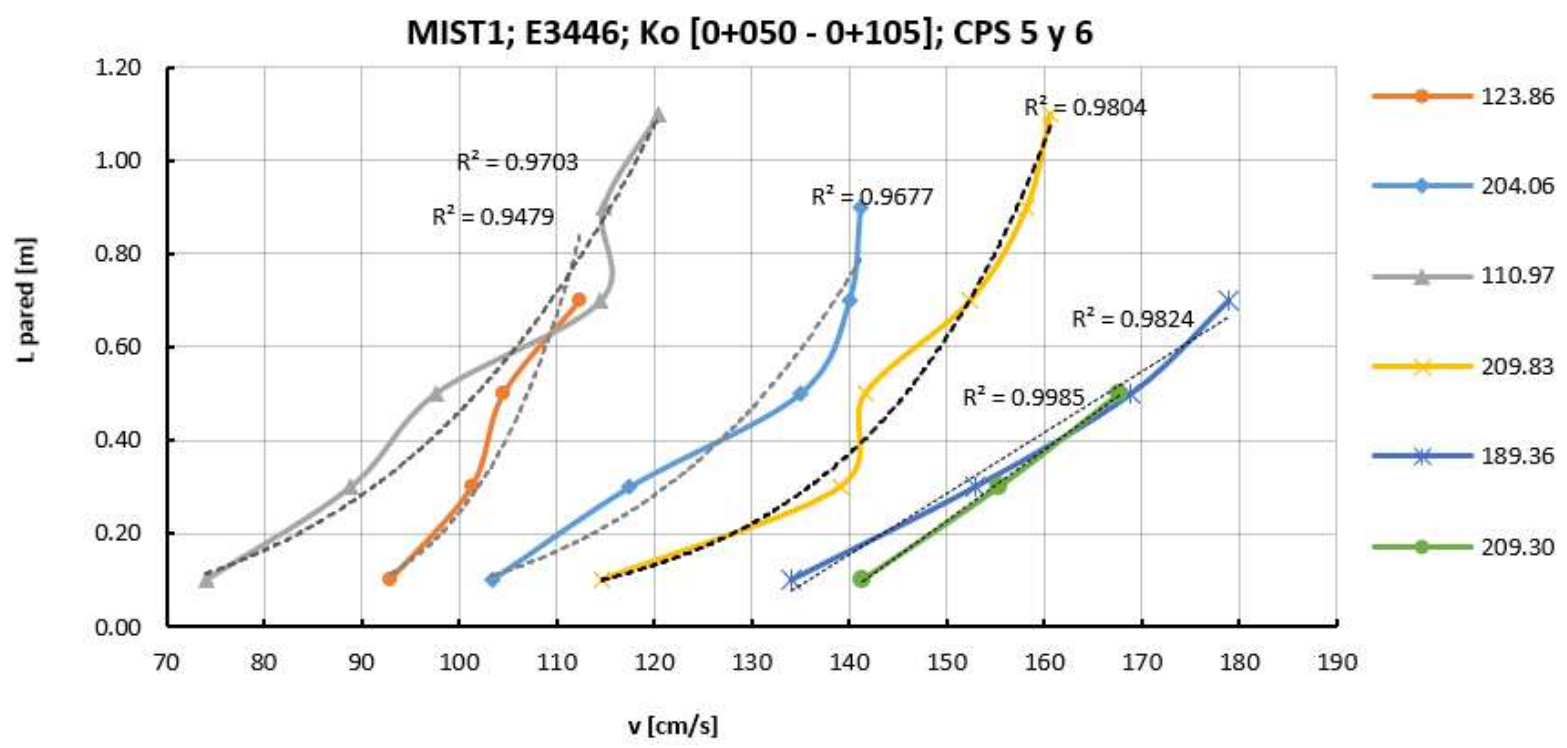

Figura 13. Perfiles de velocidad registrados por el equipo doppler para diferentes valores de gasto del medidor ubicado en la margen izquierda superior del túnel 1 (MIST1 K0+050). 


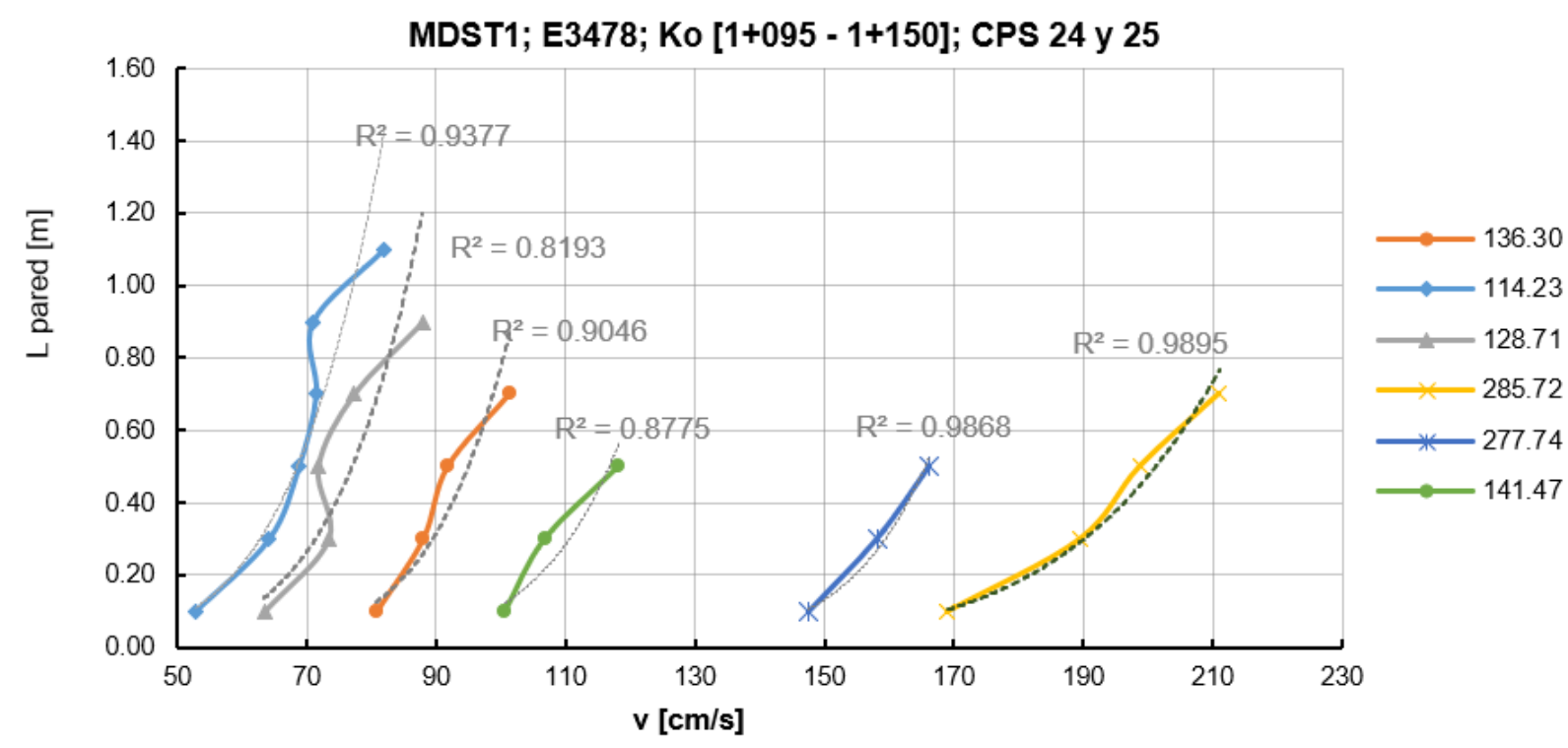

Figura 14. Perfiles de velocidad registrados por el equipo doppler para diferentes valores de gasto del medidor ubicado en la margen derecha superior del túnel 1 (MDST1 K1+095). 
Tecnologíay

Ciencias $\overline{\text { Agua }}$
2022, Instituto Mexicano de Tecnología del Agua

Open Access bajo la licencia CC BY-NC-SA 4.0 (https://creativecommons.org/licenses/by-nc-sa/4.0/)

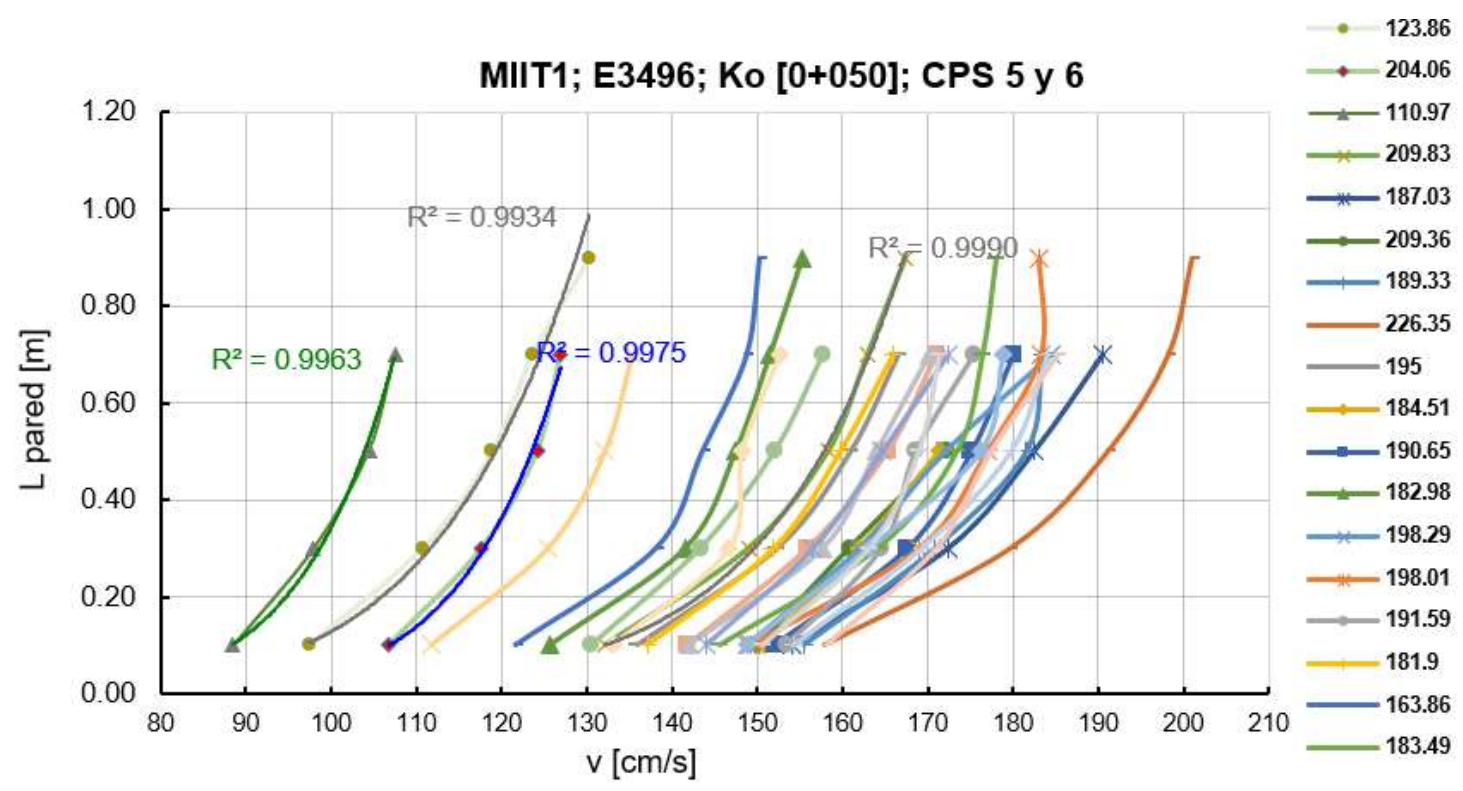

Figura 15. Perfiles de velocidad registrados por el equipo doppler para diferentes valores de gasto del medidor ubicado en la margen izquierda inferior del túnel 1 (MIIT1).

Se hicieron estimaciones para diferentes tirantes y se observó que el espesor de desplazamiento $(\delta d)$ era del orden del $10 \%$ del valor del tirante medido (Figura 16). 
Tecnología y

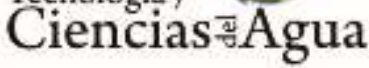

2022, Instituto Mexicano de Tecnología del Agua

Open Access bajo la licencia CC BY-NC-SA 4.0 (https://creativecommons.org/licenses/by-nc-sa/4.0/)

\begin{tabular}{|c|c|c|c|c|c|c|c|c|c|c|c|c|c|c|c|c|c|c|c|c|c|}
\hline 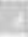 & c & H & 1 & r & K & f & M & N & e & $y$ & 4s & sH & Ai & N & ak & $N$ & an. & As. & 20 & Ali & Aa \\
\hline \multicolumn{22}{|l|}{1} \\
\hline 2 & \multicolumn{21}{|c|}{ INFORMACIÓN PROVENIENTE DE ARGONAUTS EN TUNEL, 1 Y DE CELD, } \\
\hline 3 & & & & & & & & & & & & & & & & & vosin & $\operatorname{sing}$ & m & & \\
\hline A & renease on: & HaLnLogames & & & & & & & & & & & & & & & คess & 9093 & ma! & & \\
\hline 1 & & & & \multicolumn{7}{|c|}{ Usadán } & & & & & & \multicolumn{4}{|c|}{ TVEan * 1 t5Tat by } & & \\
\hline 0 & & & 142 & 1 & 2 & 3 & 4 & & ! & \multirow{3}{*}{$\kappa$} & & & & & & & 1 Ba: & 1021 & ma & & \\
\hline 7 & & & tane & wnt & m & uant & $\cos \pi$ & $0 * 450$ & mos & & & & & & & & & & & & \\
\hline n & & & & Fat & Diul & Ditas & fire & CHSS & Cosi & & & & & & & & & & & & \\
\hline 3 & \multirow{2}{*}{ Netwo } & cabs & 0 & \multicolumn{7}{|c|}{ i } & \multicolumn{10}{|c|}{ This Cel bois, Speot itwisi } & \multirow{2}{*}{ Iod } \\
\hline 10 & & intavir & why & $h=35$ & $n \rightarrow \infty$ & has & aะta & $\pi$ & $m$ & $\begin{array}{l}\text { Trame } \\
\text { suasas. }\end{array}$ & 1 & 2 & 3 & 4 & 5 & 0 & I & \pm & 0 & 17 & \\
\hline 11 & & octuibeasos covts & & & & & & & & & 61 & os & 80 & b.) & is & 11 & 13 & 10 & 17 & 19 & \\
\hline 12 & TW01AW5 & \multirow{4}{*}{ 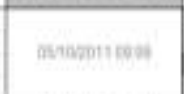 } & (160: & . & + & 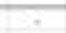 & 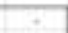 & . & 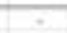 & 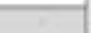 & 36.25 & 825 & 184 & $4 \pi$ & 1006 & 10ratie & $11 \times 3$ & t1r.es & n1.48 & 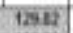 & तisin \\
\hline (1) & 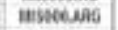 & & (e) 30 & . & s. & . & . & . & . & tes & 700 & $36 n$ & 1201 & 1030 & 11210 & 1254 & $n a n$ & $\operatorname{sxn}$ & 1stors & $\operatorname{1xn}$ & $\sin$ \\
\hline 14 & Hewet6an & & Lines & . & & . & . & - & $=$ & $x^{2}$ & 12 : & 10436 & no.n & $\min x$ & 12tas & 130.10 & 12e日 & $112 \pi$ & 12032 & 120.4 & ase \\
\hline 15 & 100000 or & & (19i0) &. & + & 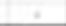 & 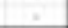 &. & 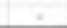 & 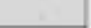 & 1671 & itai & $n \pi 1$ & 102. 4 & 1000 & 107.4 & 1938 & $122 n$ & 120 & 12260 & UEas \\
\hline 16 & Hoscowarg & 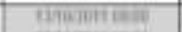 & समिता & 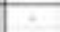 & . & $*$ & - & . & . & - & 227 & 64.69 & $\operatorname{sen}$ & 110 & 76.97 & 11.35 & कि.4 & 104 & $102 \pi$ & 1625 & abt \\
\hline 17 & abscosarg & 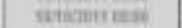 & $\sin$ & . & . & . & . & . & . & . & siss & nai & $n \cdot n$ & $n x$ & tat & nus & $\operatorname{sen} 3$ & 10215 & $\tan 23$ & 10720 & $\operatorname{ten} 5$ \\
\hline 115 & apsiotiary & 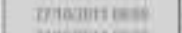 & $21 \times n$ & $=$ & 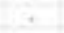 & 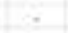 & ? & - & . & 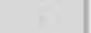 & 1eacs & $\operatorname{lig} 4$ & 150 & 2142 & Her & 22916 & 240 s & zeses & 2515 & 25020 & $6 \cos$ \\
\hline 19 & Gostor aip & 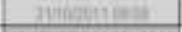 & initis & $=$ & . & $\therefore$ & + & - & + & 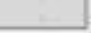 & 1674 & 1540 & 10631 & ifin & 10011 & 144 & 2657 & 2121 & 21315 & 2815 & Uise \\
\hline 20 & & 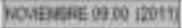 & & & & & & & & & & & & & & & & & & & \\
\hline 24 & Bostoreng & 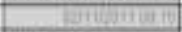 & phian & 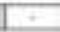 & + & + & + & 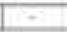 & + & 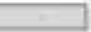 & 10065 & 1000 & 11622 & $92 \pi$ & (2): & 10216 & 109 & $1 \times 15$ & (10) & काता & (1.2. \\
\hline 22 & & 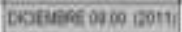 & & & & & & & & & & & & & & & & & & & \\
\hline a) & Twatcenave & \multirow{4}{*}{ sylagph an } & काल4 & का & & Z. & . & 5201 & क552 & काm & Wen & 11060 & सक्म & 12262 & 19029 & 1520 & मझल & कर्भ & कब9 & हल० & (19) \\
\hline 24 & (2)93003 ing & & Tמ⿵冂卄 & 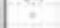 & a & $=$ & \% & $2: 0 \mathrm{r}$ & $\operatorname{sen} 2$ & aोint & 3304 & 10ras & 1048 & $192 \pi$ & mos & aи & 1204 & $\operatorname{tas} 2$ & 1252 & 1206 & 0.000 \\
\hline Bs & บpoons $x$ & & isiat & . & ? & ok & ? & ater. & $\operatorname{sos2}$ & inent & nssi & 7000 & 284 & an & 3402 & as.s. & हi & E7 & nii & iss & 0400 \\
\hline 25 & 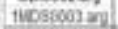 & & inat & & . & 3 & ok & asb & inis & & 800 & wy & in & inot & 801 & ai & 1524 & itof & 1122 & nis & atia \\
\hline$\eta$ & ivescer ing & \multirow{4}{*}{ 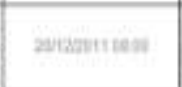 } & 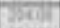 & WK & 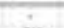 & $=$ & . & D. & $\ln 5$ & IIIt) & 1607 & 187 - & $6 x+1$ & 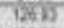 & Dith & 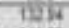 & 1. & $10 \times 43$ & DNy & 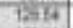 & विक्षि \\
\hline 30 & 165ecosaig & & isoul & 4 & $c i$ & & ? & a) & istiv & sens & 1039 & 117.52 & ixis & 19ane & 141.60 & 1etis & wens & $152 \mathrm{~m}$ & $15 u 4$ & 1504 & in \\
\hline 8 & 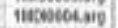 & & Theit & ? & 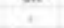 & ok & & 2,206 & E.Mi & signs & 104 ? & ห.. & WA & Wai & 1006 & ins & $055^{\prime}$ & แas & ini & 16.2 & ing \\
\hline ii) & thostoos $=$ & & zanet & & 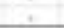 & $\div$ & OK & 2200 & E.ti & Ging & mai & $\mathrm{mn}$ & itis & 107.25 & i111 & 1125 & 1203 & 193 & inie & 110.45 & 6314 \\
\hline II & Tuitor in & \multirow{4}{*}{ zysmont ent } & & कर & $\div$ & 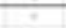 & & कासी & क2il & तो & Tहित & ins & 1002 & 1015 & iiv & किसी & 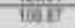 & Hif & 1004 & 602 & if \\
\hline 12 & 16satos an & & nest & . & at & & I. & 2211 & 228 & siteis & H. & ix: & vai & 11054 & 114 & 12010 & $\$ 19.36$ & itest & nase & 12006 & U⿻丷木 \\
\hline 33 & SDov04 arg & & Beis. & . & ? & ok & 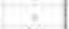 & जat & 2210 & Yinat & $n n$ & ison & 784 & 150 & 71 & eai & nai & ris & ist & ist & ilitar \\
\hline 34 & 118secos $=4$ & & (nea) & $=$ &. & $=$ & ok & 2.211 & E216 & singat & (11) & 78.4 & $\log$ & $\mathrm{Bi}$ & Ber & it & 821 & 4.71 & 10.4 & 432 & $\cos r$ \\
\hline $\mathrm{B}$ & & DUEF & & & & & & & & & $70 v$ & 169 & Whil & 1145 & $114 \pi$ & 12030 & 11936 & 11451 & 11410 & 1204 & \\
\hline \multicolumn{22}{|l|}{ is } \\
\hline 37 & & 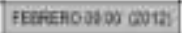 & & & & & & & & & & & & & & & & & & & \\
\hline a & 1matcotarg & \multirow{4}{*}{ 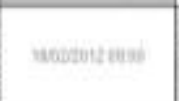 } & 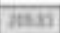 & $\mathrm{OH}$ & . & . & + & DSA & 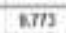 & ज्याता & 1921 & 1486 & 1918 & 169.3 & बात्म & 1es? & 1615 & $16 \times n$ & 180 & 16176 & $\mathrm{D} . \mathrm{II}$ \\
\hline na & 1tesacotais & & bens & . & cir &. & s. & enso & $\mathrm{sm}$ & sตับ & Hats & 19911 & 14..65: & 15240 & 16ez4 & 1604 & 10440 & mais & 1e4t & $168 \mathrm{Ar}$ & 100 \\
\hline (ii) & mobebtare & & inas & 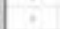 & & oK & 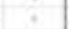 & 2250 & $m$ & หม่า: & $\tan$ & 12200 & 12520 & 2431 & 19us & 1261 & $\tan 1$ & tets & tasta & 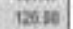 & $n \sin$ \\
\hline 31 & "11085001 ime & & matif & ?. & . & . & ok & 1798 & $m$ & vomi: & 11351 & 12520 & 104 & 1982 & ini & 1663 & 142.2 & Wat & 1026 & 1671 & 0840 \\
\hline
\end{tabular}

Figura 16. Revisión del espesor de desplazamiento $\delta d$.

Aplicando la Ecuación (22) y la metodología descrita en el subcapítulo de "Rugosidad equivalente de Nikuradse $k s$ " se obtuvieron valores de rugosidad de pared $n_{\text {pared }}$ (Tabla 4, Figura 17, Figura 18, Figura 19, Figura 20), para los equipos doppler instalados localizados en los cadenamientos K0+050 y K1+115 del túnel 1 y localizados a diferentes alturas: MII T1 es margen izquierda inferior del túnel $1(h=2.5 \mathrm{~m})$; MIS 
T1 es margen izquierda superior del túnel $1(h=5.5 \mathrm{~m})$; MDI T1 es margen derecha inferior del túnel $1(h=4 \mathrm{~m})$; MDS T1 es margen derecha superior del túnel $1(h=7 \mathrm{~m})$.

Tabla 4. Valores de rugosidad de pared ( $n_{\text {pared }}$ ) en concreto lanzado para los doppler en el $\mathrm{K} 0+050$ y el $\mathrm{K} 1+115$.

\begin{tabular}{|l|l|l|c|}
\hline \multicolumn{2}{|c|}{ Sección 0+050 } & $n_{\text {pared }}$ & $\boldsymbol{h}(\mathbf{m})$ \\
\hline MII T1 & E3496 & 0.0121 & 2.5 \\
\hline MIS T1 & E3446 & 0.0154 & 5.5 \\
\hline MDI T1 & E3449 & 0.0104 & 4 \\
\hline MDS T1 & E3488 & 0.0193 & 7 \\
\hline
\end{tabular}

\begin{tabular}{|c|c|c|c|}
\hline \multicolumn{2}{|c|}{$\begin{array}{c}\text { Sección } \\
1+115\end{array}$} & $n_{\text {pared }}$ & $\begin{array}{c}\text { h } \\
\text { (m) }\end{array}$ \\
\hline $\begin{array}{c}\text { MII } \\
\text { T1 }\end{array}$ & E3465 & 0.0278 & 2.5 \\
\hline $\begin{array}{c}\text { MIS } \\
\text { T1 }\end{array}$ & E3497 & 0.0174 & 5.5 \\
\hline $\begin{array}{c}\text { MDI } \\
\text { T1 }\end{array}$ & E3479 & 0.0139 & 4 \\
\hline $\begin{array}{c}\text { MDS } \\
\text { T1 }\end{array}$ & E3478 & 0.0134 & 7 \\
\hline
\end{tabular}


Tecnología y

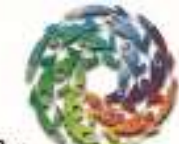

Ciencias $\sqrt{\mathrm{s}}$ Agua
2022, Instituto Mexicano de Tecnología del Agua

Open Access bajo la licencia CC BY-NC-SA 4.0 (https://creativecommons.org/licenses/by-nc-sa/4.0/)

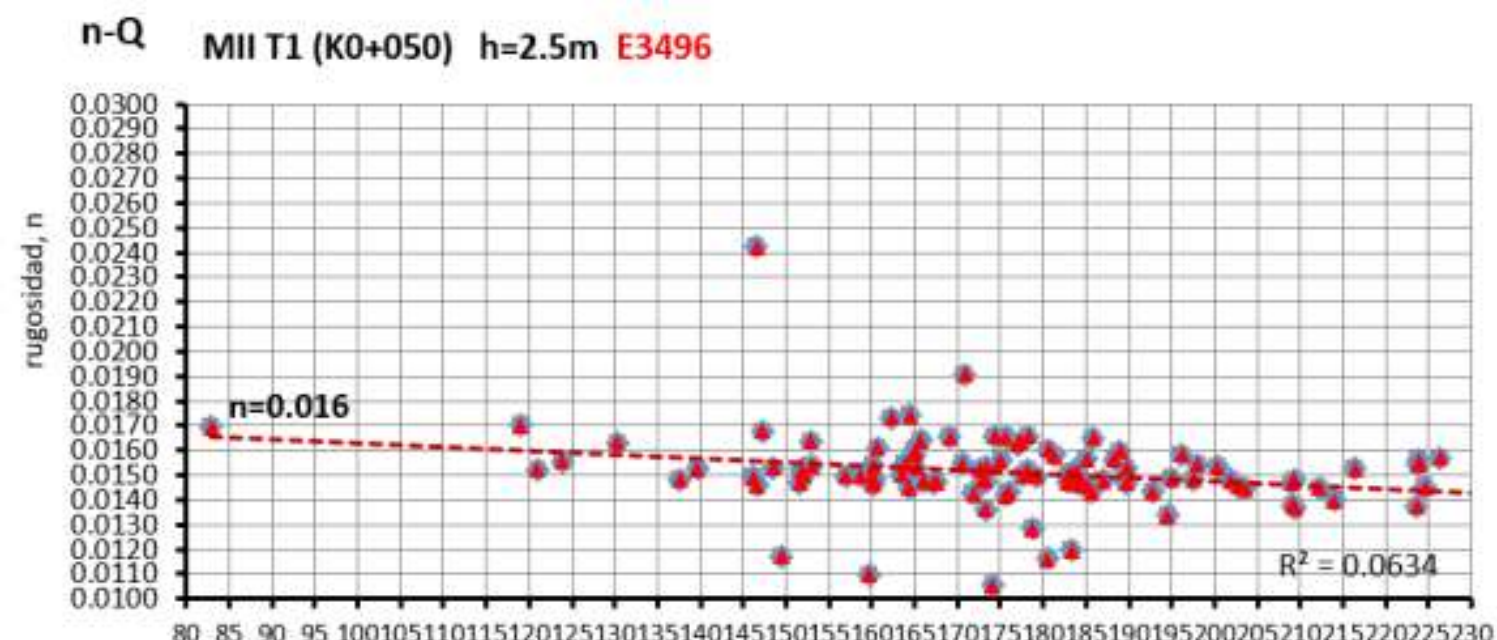

80859095100105110115120125130135140145150155160165170175180185190195200205210215220225230 Gasto $Q\left(\mathrm{~m}^{3} / \mathrm{s}\right)$

Figura 17. Rugosidad con respecto al gasto del doppler a 2.5 m (MII T1 en el $\mathrm{K} 0+050)$; rugosidad representativa $n=0.016$.

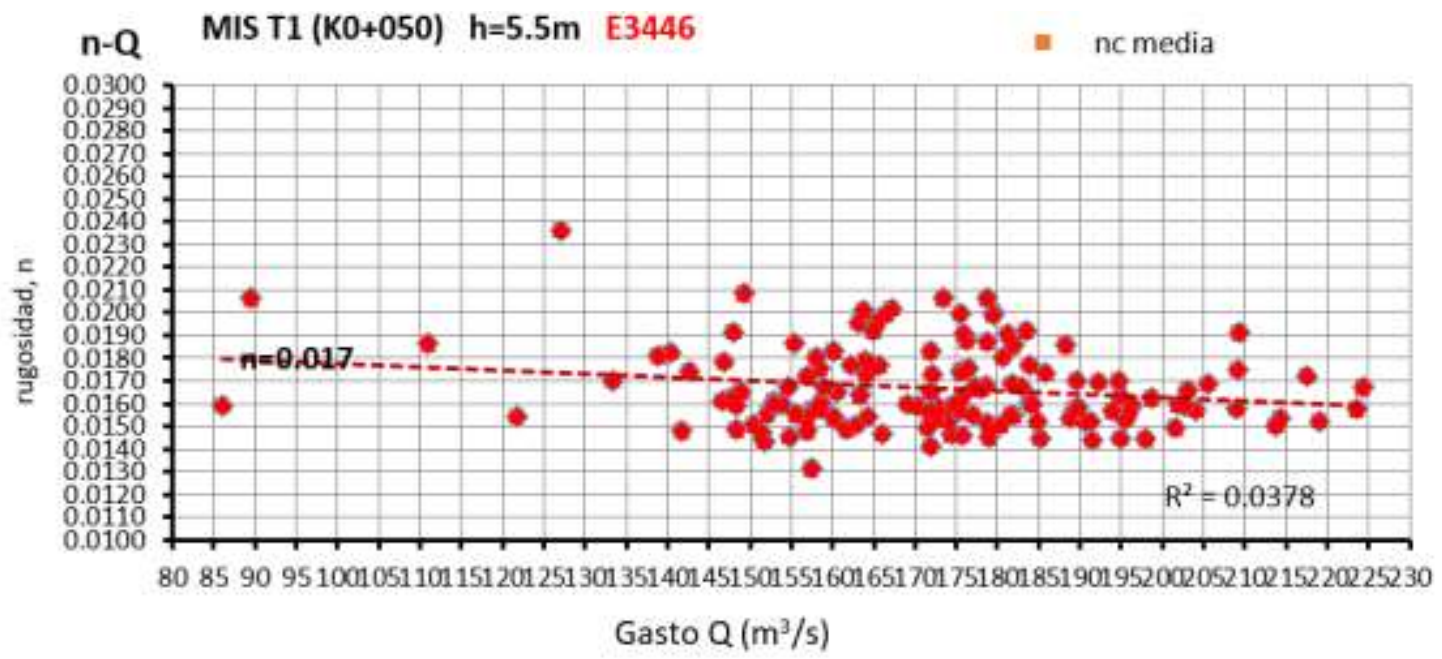

Figura 18. Rugosidad con respecto al gasto del doppler ubicado a $5.5 \mathrm{~m}$ (MIS T1 en el K0+050); rugosidad representativa $n=0.017$. 
Tecnologíay

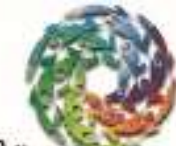

Ciencias $\overline{\text { Agua }}$
2022, Instituto Mexicano de Tecnología del Agua

Open Access bajo la licencia CC BY-NC-SA 4.0 (https://creativecommons.org/licenses/by-nc-sa/4.0/)

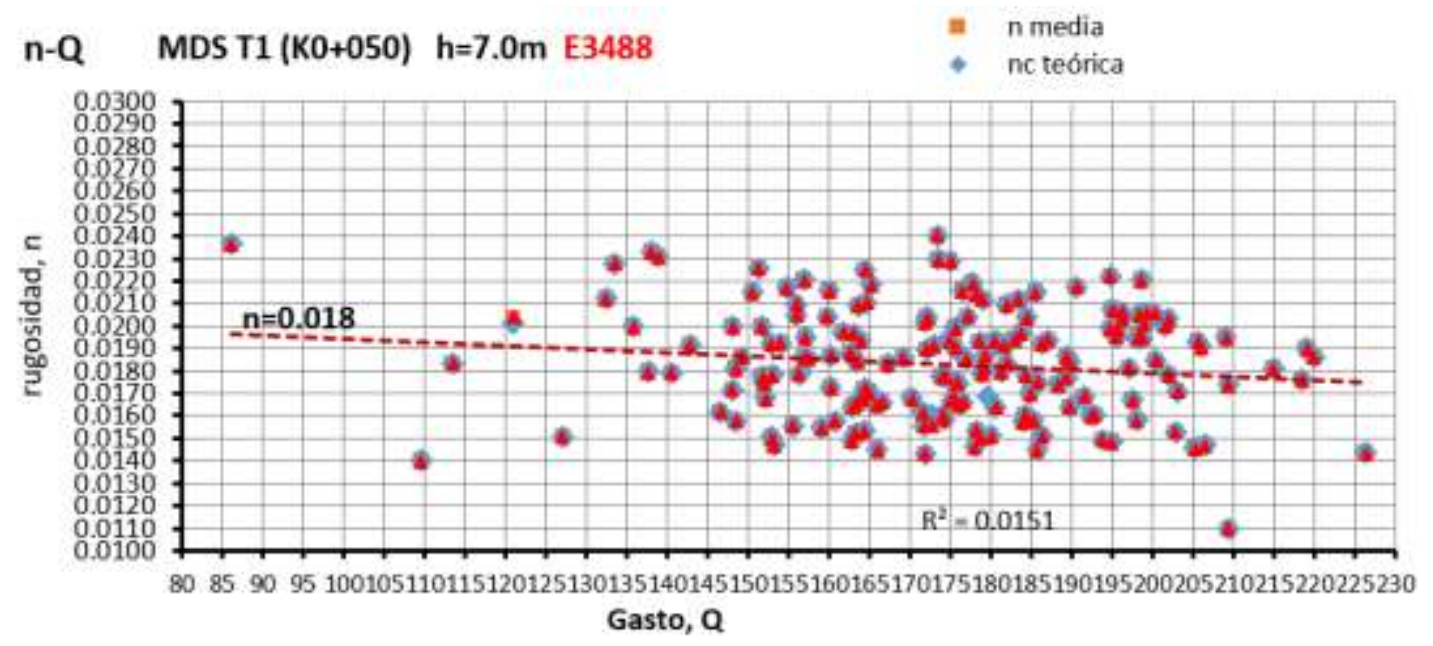

Figura 19. Rugosidad con respecto al gasto del doppler a 7 m (MDS T1 en el $\mathrm{K0}+050)$; rugosidad representativa $n=0.018$.

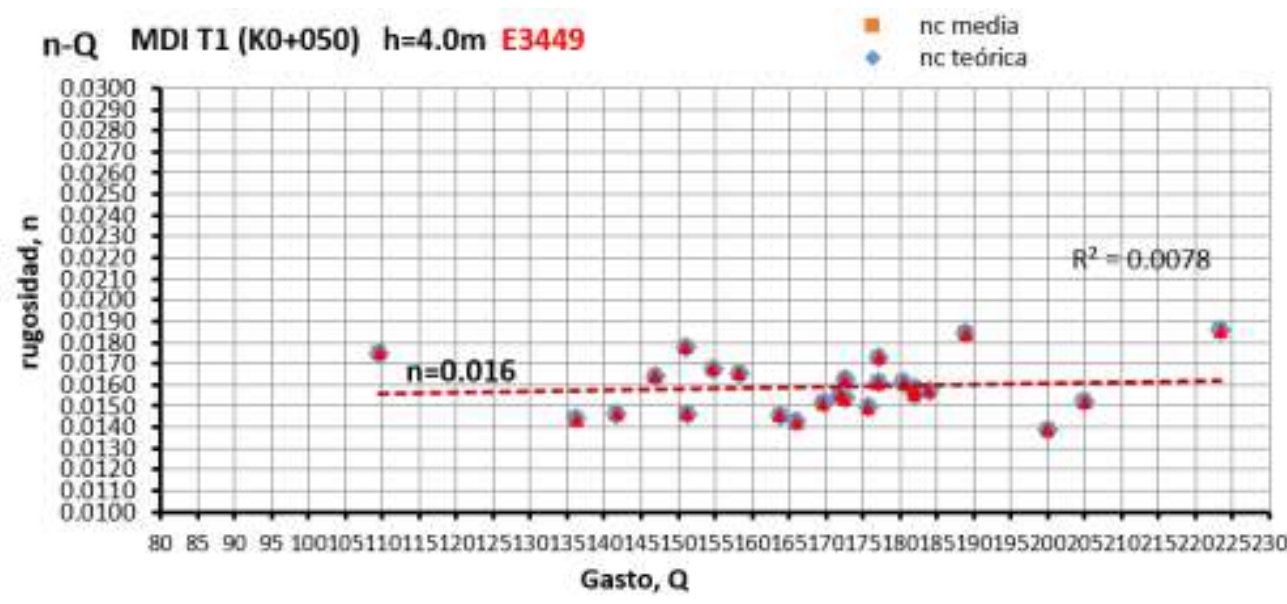


Tecnologíay

Ciencias $\approx$ Agua
2022, Instituto Mexicano de Tecnología del Agua

Open Access bajo la licencia CC BY-NC-SA 4.0 (https://creativecommons.org/licenses/by-nc-sa/4.0/)

Figura 20. Rugosidad con respecto al gasto del doppler a 4 m (MDI T1 en el $\mathrm{K} 0+050)$; rugosidad representativa $n=0.016$.

Respecto al tirante, se observa que la rugosidad no cambia de forma significativa, como lo es con los gastos, aun cuando se incremente en 30 $\mathrm{cm}$. La rugosidad representativa está en el rango de $n=0.019$ (Figura 21, Figura 22 y Figura 23).

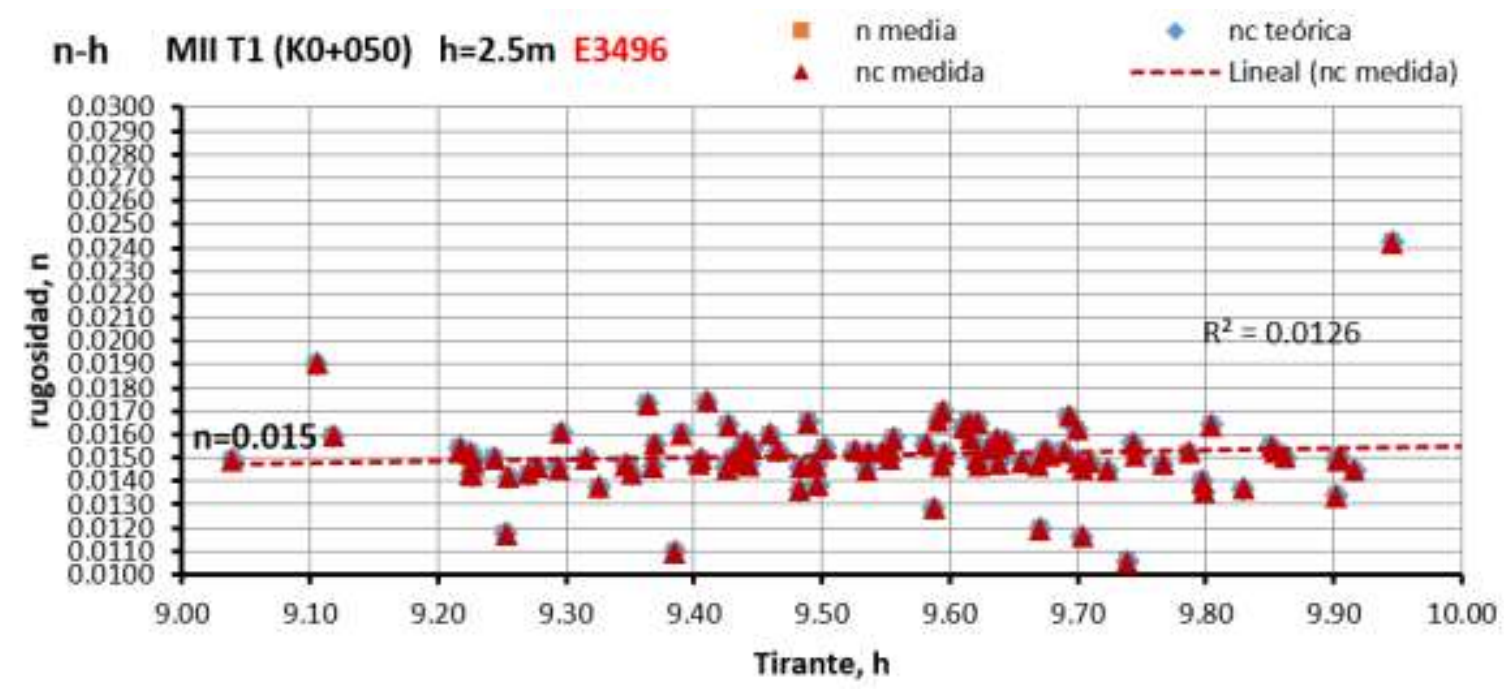

Figura 21. Rugosidad con respecto al tirante obtenida del doppler a 2.5 m (MII T1 en el K0+050); rugosidad representativa $n=0.015$. 
Tecnologíay

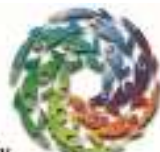

Ciencias
2022, Instituto Mexicano de Tecnología del Agua

Open Access bajo la licencia CC BY-NC-SA 4.0 (https://creativecommons.org/licenses/by-nc-sa/4.0/)

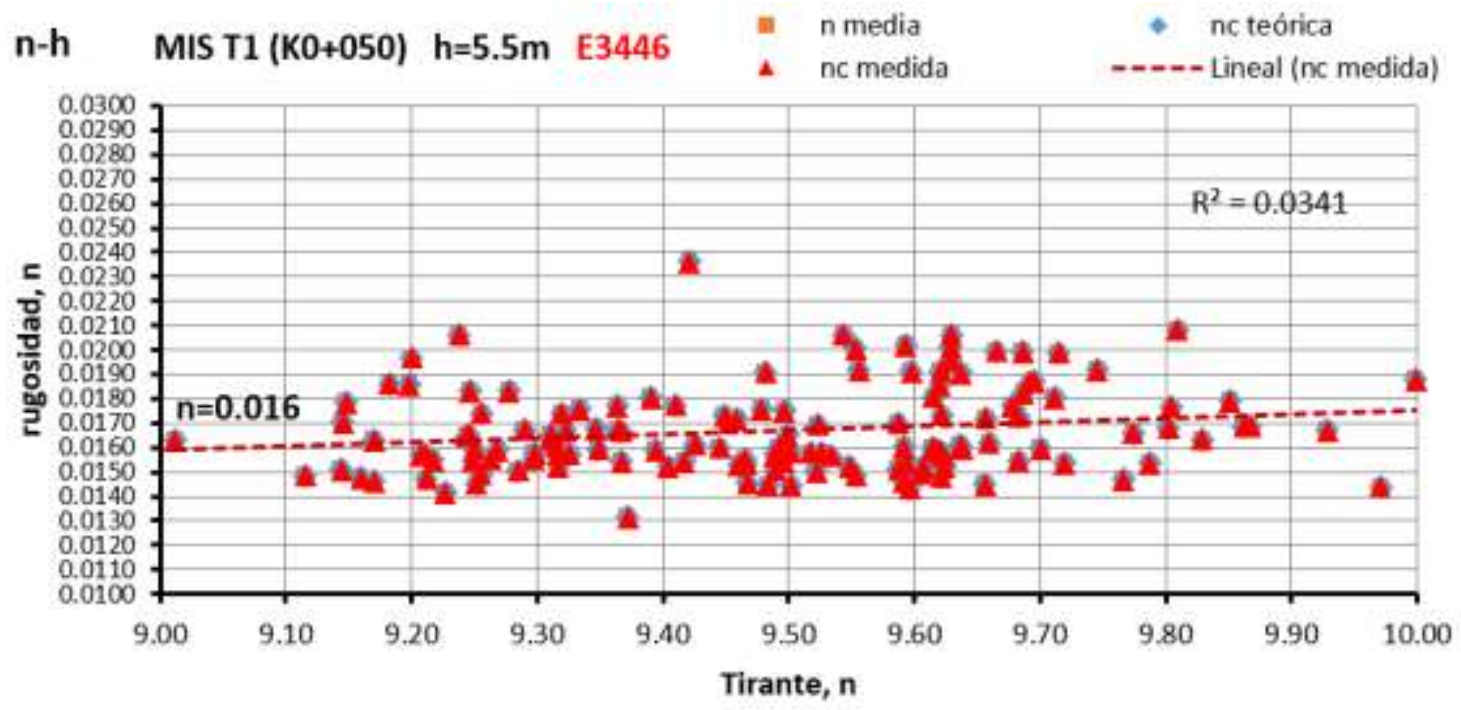

Figura 22. Rugosidad con respecto al tirante obtenida del doppler a 5.5 m (MIS T1 en el K0+050); rugosidad representativa $n=0.016$. 
Tecnología y

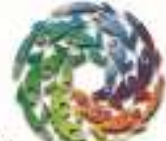

Ciencias
2022, Instituto Mexicano de Tecnología del Agua

Open Access bajo la licencia CC BY-NC-SA 4.0 (https://creativecommons.org/licenses/by-nc-sa/4.0/)

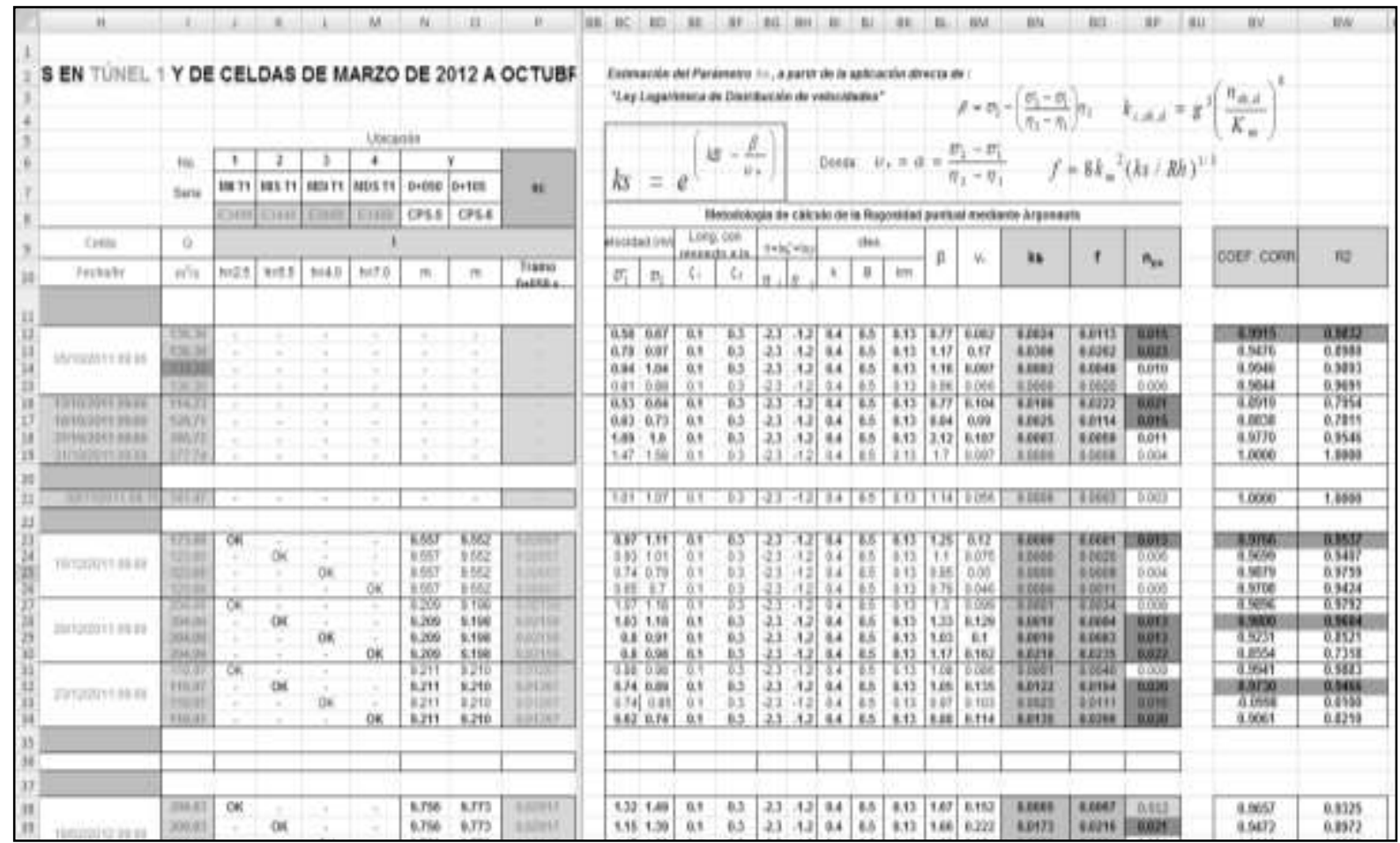

Figura 23. Cálculo de la rugosidad equivalente $k s$, y los parámetros $f$ y $n$.

Asimismo, se observa que la rugosidad varía ligeramente en las zonas de casquillo: $\mathrm{K} 0+160$ al $\mathrm{K} 0+215$ y del $\mathrm{K} 0+380$ al $\mathrm{K} 0+435$, estas zonas tienen revestimiento de concreto liso, pues están reforzadas estructuralmente (Figura 24). 
Tecnologíay

Ciencias $\approx$ Agua
2022, Instituto Mexicano de Tecnología del Agua

Open Access bajo la licencia CC BY-NC-SA 4.0 (https://creativecommons.org/licenses/by-nc-sa/4.0/)

\begin{tabular}{|c|c|c|c|c|}
\hline \multicolumn{2}{|c|}{ Sección } & Celda & Cad. & Rugosidad \\
\hline \multirow{10}{*}{ 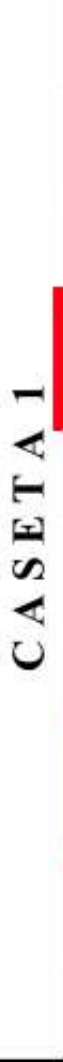 } & $\begin{array}{l}1 \\
2\end{array}$ & $\begin{array}{l}\text { CPS - } 4 \\
\text { CPS - } 5\end{array}$ & $\begin{array}{l}0+007 \\
0+050\end{array}$ & $\begin{array}{l}\text { Concreto Hidráulico } \\
\text { Concreto Lanzado }\end{array}$ \\
\hline & $\begin{array}{l}2 \\
3 \\
\end{array}$ & $\begin{array}{l}\text { CPS - } 5 \\
\text { CPS }-6 \\
\end{array}$ & $\begin{array}{l}0+050 \\
0+105 \\
\end{array}$ & $\begin{array}{c}\text { Concreto Lanzado } \\
\text { Concreto Hidráulico }\end{array}$ \\
\hline & 3 & CPS - 6 & $\begin{array}{l}0+105 \\
0+160\end{array}$ & Concreto Lanzado \\
\hline & $\begin{array}{l}4 \\
5\end{array}$ & $\begin{array}{l}\text { CPS - } 7 \\
\text { CPS - } 8\end{array}$ & $\begin{array}{l}0+160 \\
0+215\end{array}$ & $\begin{array}{l}\text { Concreto Hidráulico } \\
\text { (Casquillo) }\end{array}$ \\
\hline & $\begin{array}{l}5 \\
6 \\
\end{array}$ & $\begin{array}{l}\text { CPS - } 8 \\
\text { CPS - } 9 \\
\end{array}$ & $\begin{array}{l}0+215 \\
0+270 \\
\end{array}$ & $\begin{array}{l}\text { Concreto Lanzado } \\
\text { Concreto Hidráulico }\end{array}$ \\
\hline & $\begin{array}{l}6 \\
7\end{array}$ & $\begin{array}{l}\text { CPS - } 9 \\
\text { CPS - } 10\end{array}$ & $\begin{array}{l}0+270 \\
0+325\end{array}$ & Concreto Lanzado \\
\hline & $\begin{array}{l}7 \\
8\end{array}$ & $\begin{array}{l}\text { CPS - } 10 \\
\text { CPS - } 11\end{array}$ & $\begin{array}{l}0+325 \\
0+380\end{array}$ & Concreto Lanzado \\
\hline & $\begin{array}{l}8 \\
9\end{array}$ & $\begin{array}{l}\text { CPS - } 11 \\
\text { CPS - } 12\end{array}$ & $\begin{array}{l}0+380 \\
0+435\end{array}$ & $\begin{array}{l}\text { Concreto Lanzado } \\
\text { (Casquillo) }\end{array}$ \\
\hline & $\begin{array}{c}9 \\
10\end{array}$ & $\begin{array}{l}\text { CPS - } 12 \\
\text { CPS - } 13\end{array}$ & $\begin{array}{l}0+435 \\
0+490\end{array}$ & $\begin{array}{l}\text { Concreto Lanzado } \\
\text { Concreto Hidráulico }\end{array}$ \\
\hline & $\begin{array}{l}10 \\
11\end{array}$ & $\begin{array}{l}\text { CPS - } 13 \\
\text { CPS - } 14\end{array}$ & $\begin{array}{l}0+490 \\
0+545\end{array}$ & Concreto Lanzado \\
\hline
\end{tabular}

Figura 24. Ubicación de zonas de rugosidad (concreto lanzado y concreto hidráulico).

Se muestran dos gráficas: gastos mayores a $150 \mathrm{~m}^{3} / \mathrm{s}$ (Figura 25), y gastos menores a $150 \mathrm{~m}^{3} / \mathrm{s}$ (Figura 26), donde se observan esos cambios en la rugosidad. 
Tecnologíay

Ciencias $\stackrel{\Xi}{\sim}$ gua
2022, Instituto Mexicano de Tecnología del Agua

Open Access bajo la licencia CC BY-NC-SA 4.0

(https://creativecommons.org/licenses/by-nc-sa/4.0/)

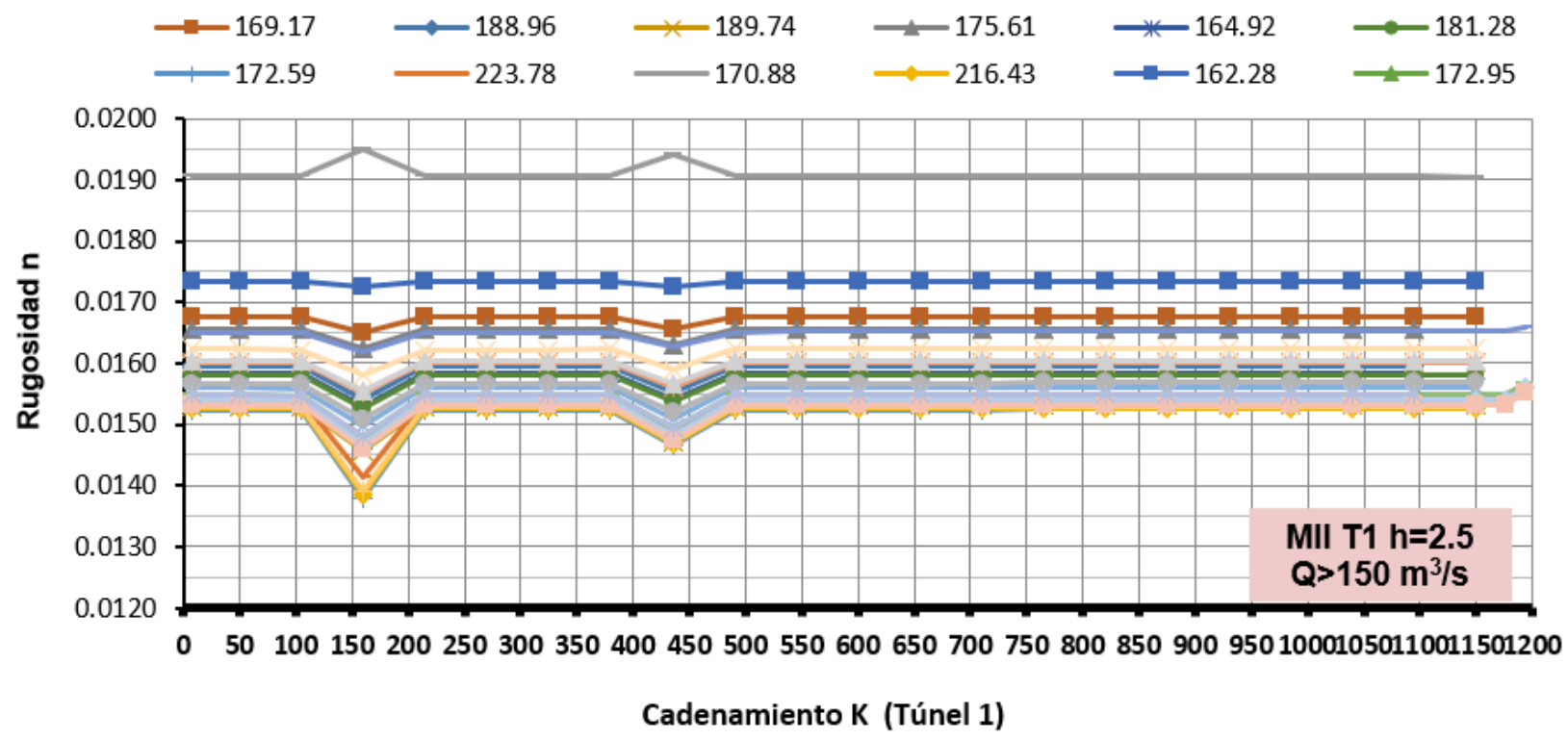

Figura 25. Rugosidad compuesta a lo largo del túnel para un $Q>150$ $\mathrm{m}^{3} / \mathrm{s}$, para el doppler a $2.5 \mathrm{~m}$ de altura. 
Tecnologíay

Ciencias $\approx$ Agua
2022, Instituto Mexicano de Tecnología del Agua

Open Access bajo la licencia CC BY-NC-SA 4.0 (https://creativecommons.org/licenses/by-nc-sa/4.0/)

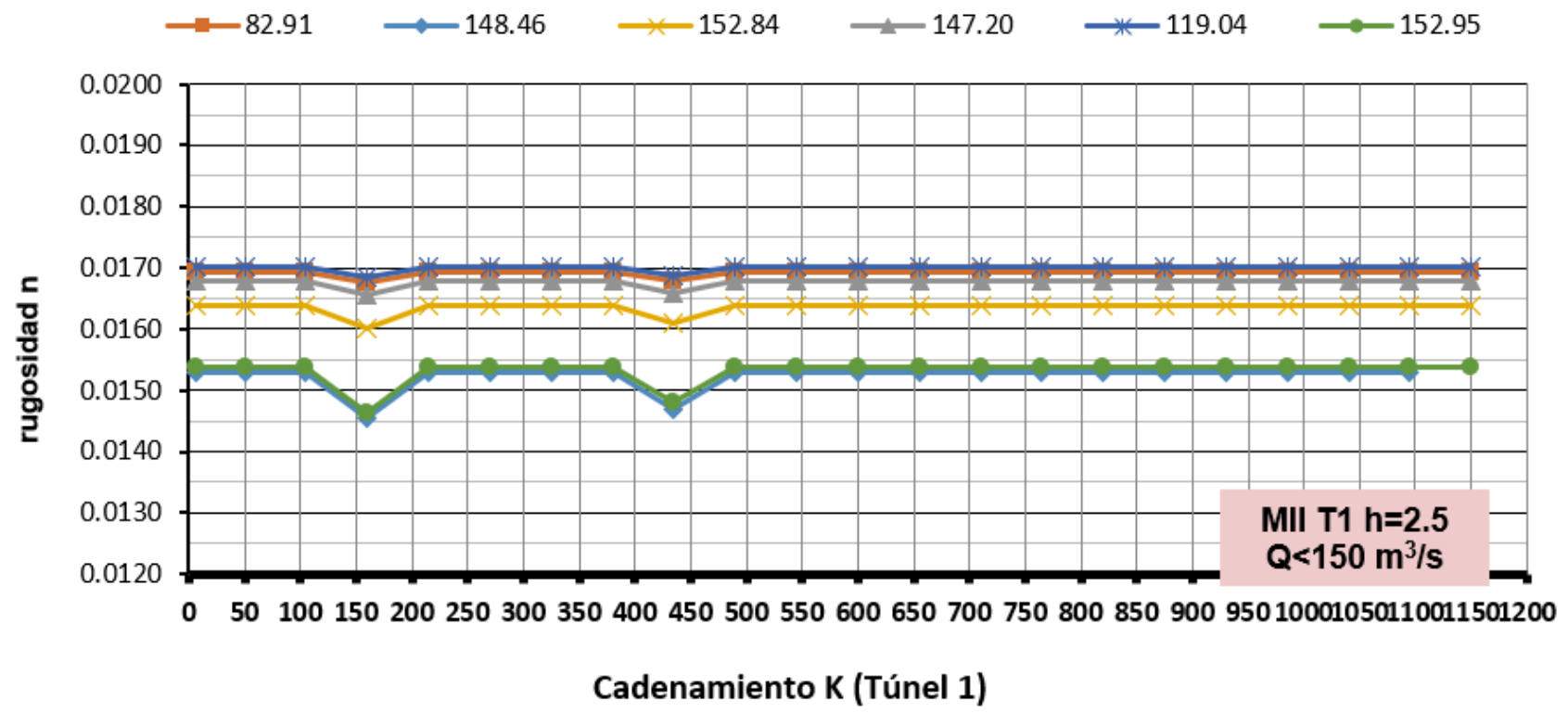

Figura 26. Rugosidad compuesta a lo largo del túnel para un $Q<150$ $\mathrm{m}^{3} / \mathrm{s}$, para el doppler a $2.5 \mathrm{~m}$ de altura.

En la Figura 27 también se observa que el gasto entre secciones se mantiene muy parecido entre la primera y la última celda para los valores tomados cada hora, por lo que se puede realizar el cálculo como flujo permanente. 


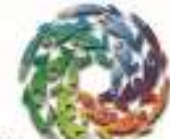
as 꼰
2022, Instituto Mexicano de Tecnología del Agua

Open Access bajo la licencia CC BY-NC-SA 4.0 (https://creativecommons.org/licenses/by-nc-sa/4.0/)

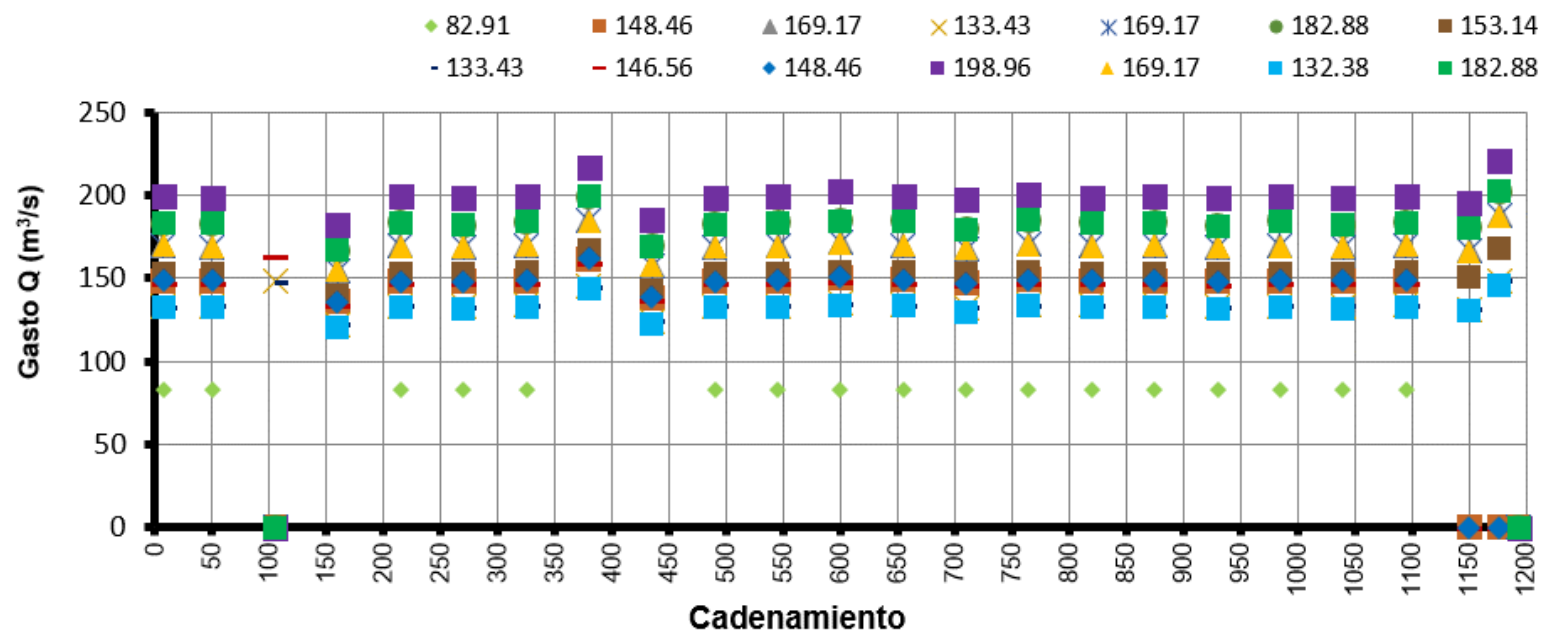

Figura 27. Gasto o caudal (por celda) a lo largo del túnel.

En la Figura 28, Figura 29, Figura 30 y Figura 31 se muestra el perfil hidráulico de algunos de los gastos modelados y calibrados; la línea azul representa el valor teórico, y los puntos negros representan los valores medidos. 
Tecnología y

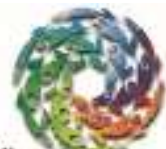

Ciencias 공ำ
2022, Instituto Mexicano de Tecnología del Agua

Open Access bajo la licencia CC BY-NC-SA 4.0

(https://creativecommons.org/licenses/by-nc-sa/4.0/)

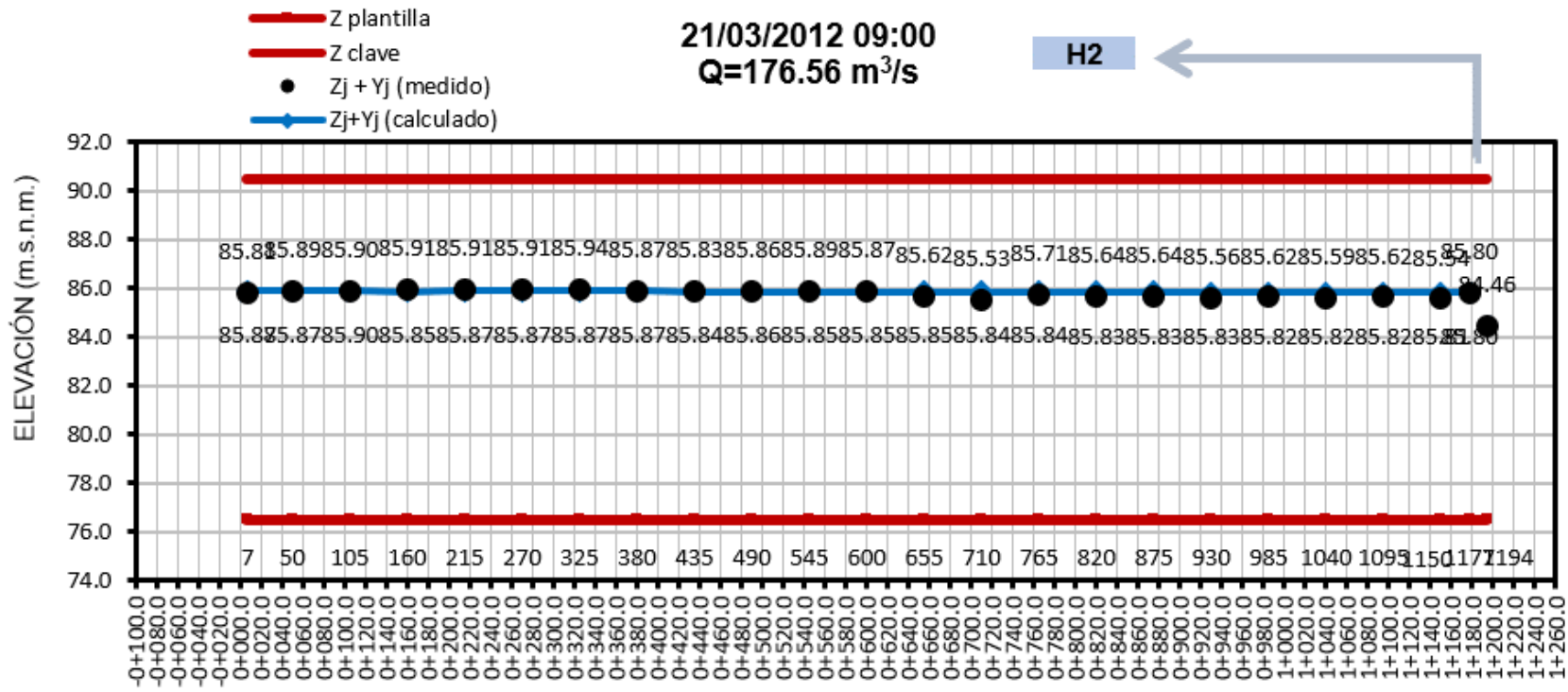

Figura 28. Calibración del modelo para un $Q=176.56 \mathrm{~m}^{3} / \mathrm{s}$.

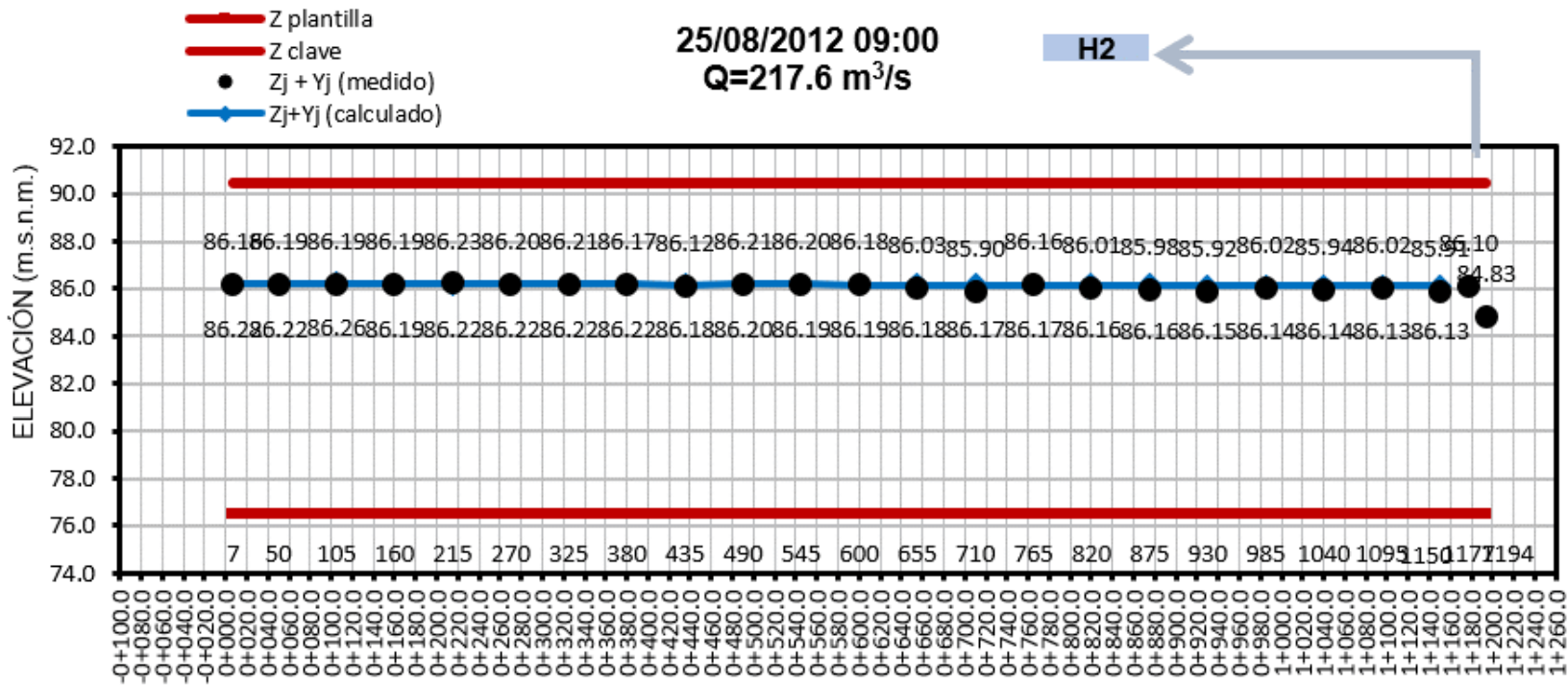

Tecnología y ciencias del agua, ISSN 2007-2422,13(2), DOI: 10.24850/j-tyca-2022-02-04 
Tecnologíay

Ciencias $\sqrt[3]{\mathrm{v}}$ Agua
2022, Instituto Mexicano de Tecnología del Agua

Open Access bajo la licencia CC BY-NC-SA 4.0

(https://creativecommons.org/licenses/by-nc-sa/4.0/)

Figura 29. Calibración del modelo para un $Q=217.6 \mathrm{~m}^{3} / \mathrm{s}$.

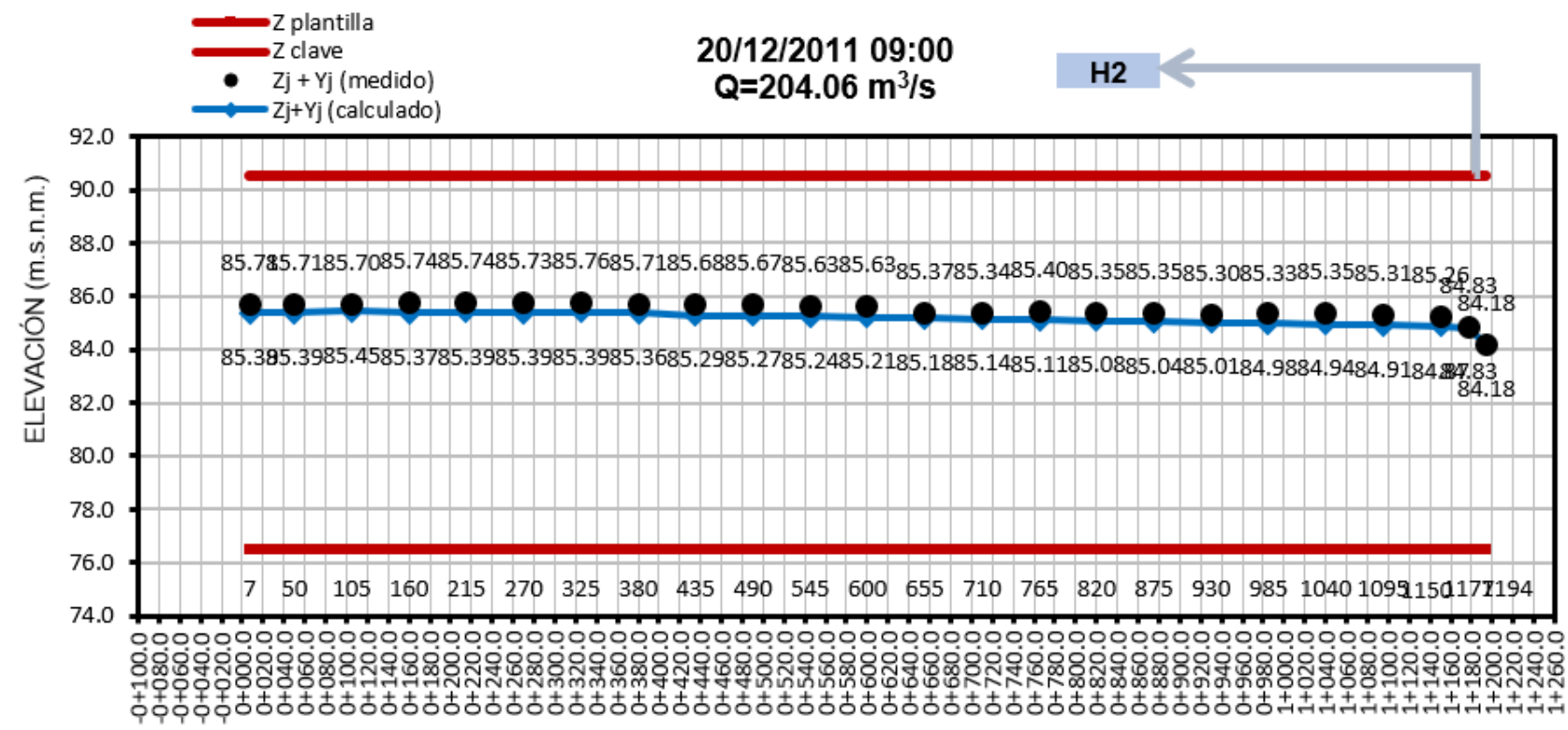

Figura 30. Calibración del modelo para un $Q=204.06 \mathrm{~m}^{3} / \mathrm{s}$. 
Tecnologíay

Ciencias $\overline{\text { ปngua }}$
2022, Instituto Mexicano de Tecnología del Agua

Open Access bajo la licencia CC BY-NC-SA 4.0 (https://creativecommons.org/licenses/by-nc-sa/4.0/)

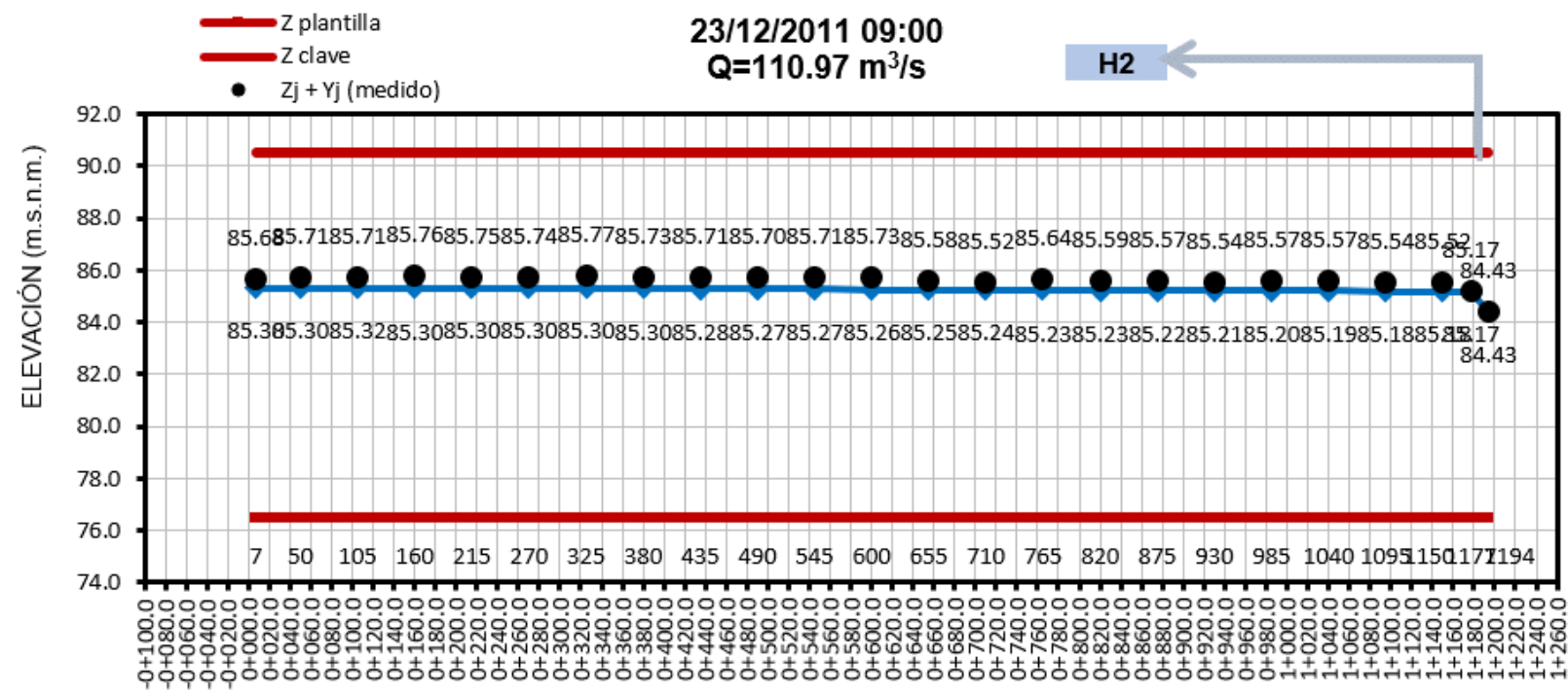

Figura 31. Calibración del modelo para un $Q=110.97 \mathrm{~m}^{3} / \mathrm{s}$.

Se revisó cada uno de los tres valores de rugosidad compuesta

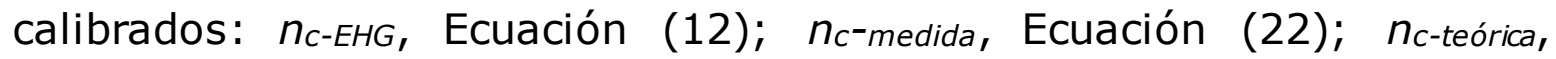
ecuaciones de la Tabla 3, identificando el mínimo error cuadrado, MEC, y para todos los cadenamientos con celda de medición de nivel. Se discretizaron e identificaron aquellos en los que se tuviera el menor valor de desviación estándar.

En los cadenamientos a lo largo del túnel se identificaron diversos valores de rugosidad. Después de discretizarlos y calibrarlos con respecto a las mediciones y al cálculo planteado con la ecuación hidráulica general, se encontraron los valores que se muestran en la Figura 32 con el mínimo 
error cuadrático por cadenamiento, que equivalen a una rugosidad compuesta media para el túnel 1 de $\mathbf{0 . 0 1 7 8}$.

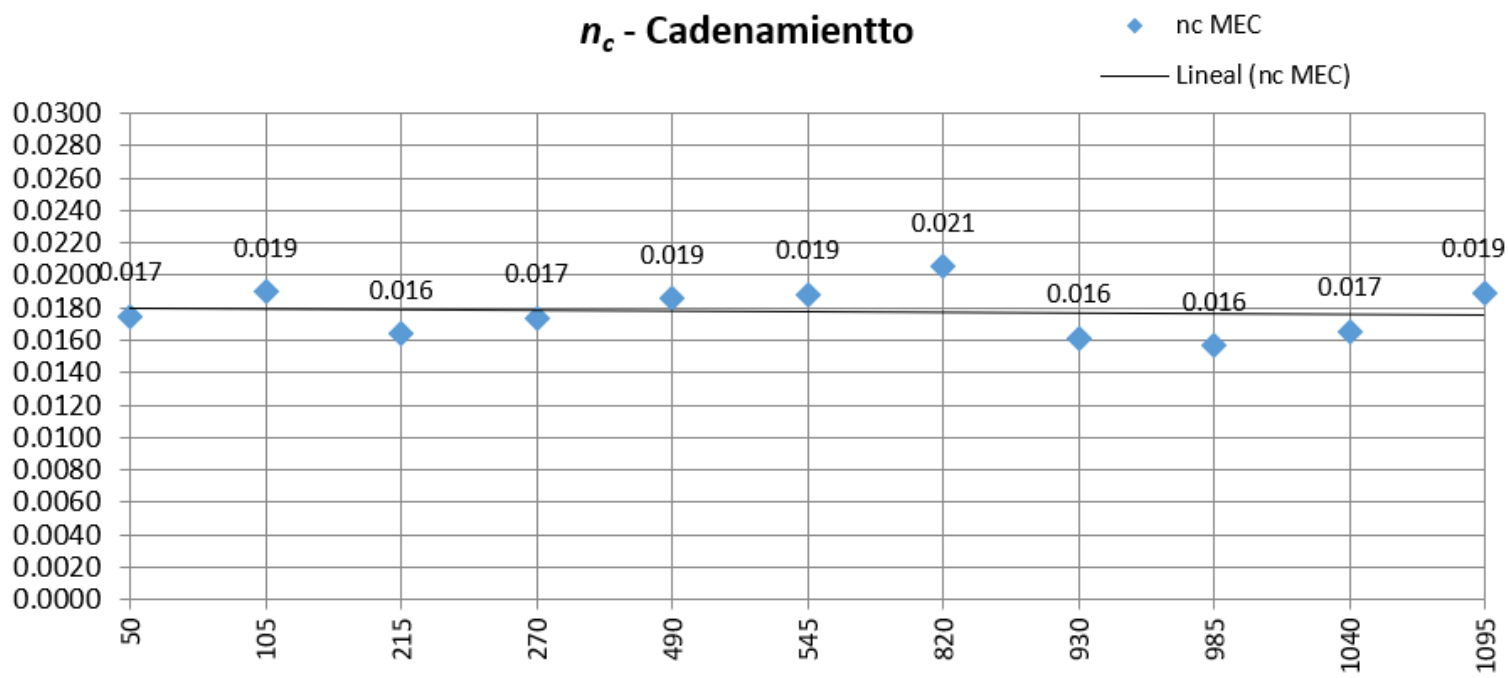

Figura 32. Rugosidad compuesta a partir del MEC por cadenamiento.

En la Figura 33 se muestra la tendencia de los valores de rugosidad compuesta obtenida para un rango de gastos de 130 a $210 \mathrm{~m}^{3} / \mathrm{s}$, y que fueron discretizados y calibrados a partir del modelo teórico y la metodología planteada para las 17 ecuaciones, así como las mediciones. 
Tecnologíay

Ciencias $\overline{\text { Agua }}$
2022, Instituto Mexicano de Tecnología del Agua

Open Access bajo la licencia CC BY-NC-SA 4.0 (https://creativecommons.org/licenses/by-nc-sa/4.0/)

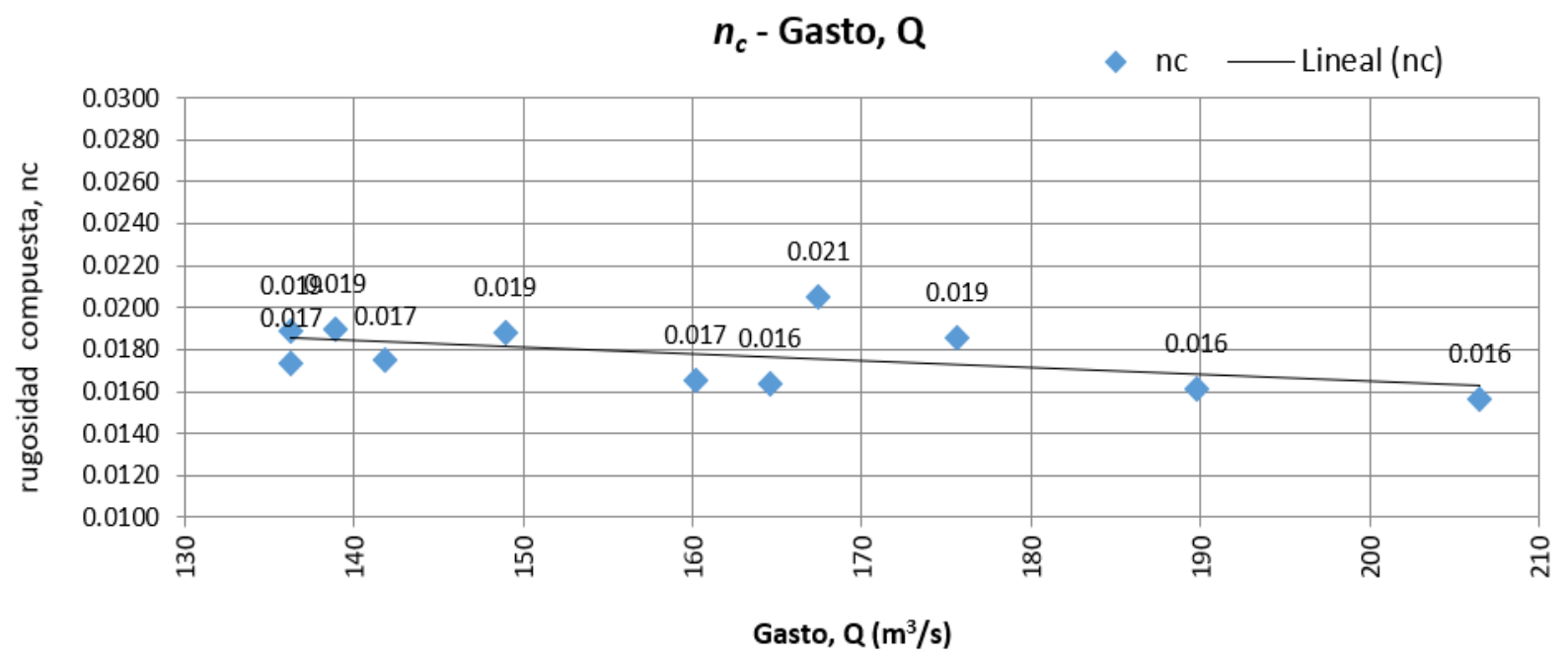

Figura 33. Rugosidad compuesta $\left(n_{c}\right)$ con respecto al gasto medido (Q).

Se identificó que la ecuación de mayor ajuste de las 17 conocidas (Tabla 3) es la que se identifica con la letra "I" para un rango de gastos que van desde 85 hasta $285 \mathrm{~m}^{3} / \mathrm{s}$ :

Ecuación I (15) (Chie-Yen, 2002):

$I=n_{c}=\left[\frac{R^{1 / 3}}{P} \sum \frac{n_{i}^{2} P_{i}}{R_{i}^{1 / 3}}\right]^{1 / 2}$ 
Tecnología y

Ciencias $\stackrel{\Xi}{\simeq}$ gua
2022, Instituto Mexicano de Tecnología del Agua

Open Access bajo la licencia CC BY-NC-SA 4.0 (https://creativecommons.org/licenses/by-nc-sa/4.0/)

En la Figura 34 se muestran las ecuaciones de rugosidad compuesta $n_{c}$ de mejor ajuste para cada gasto.

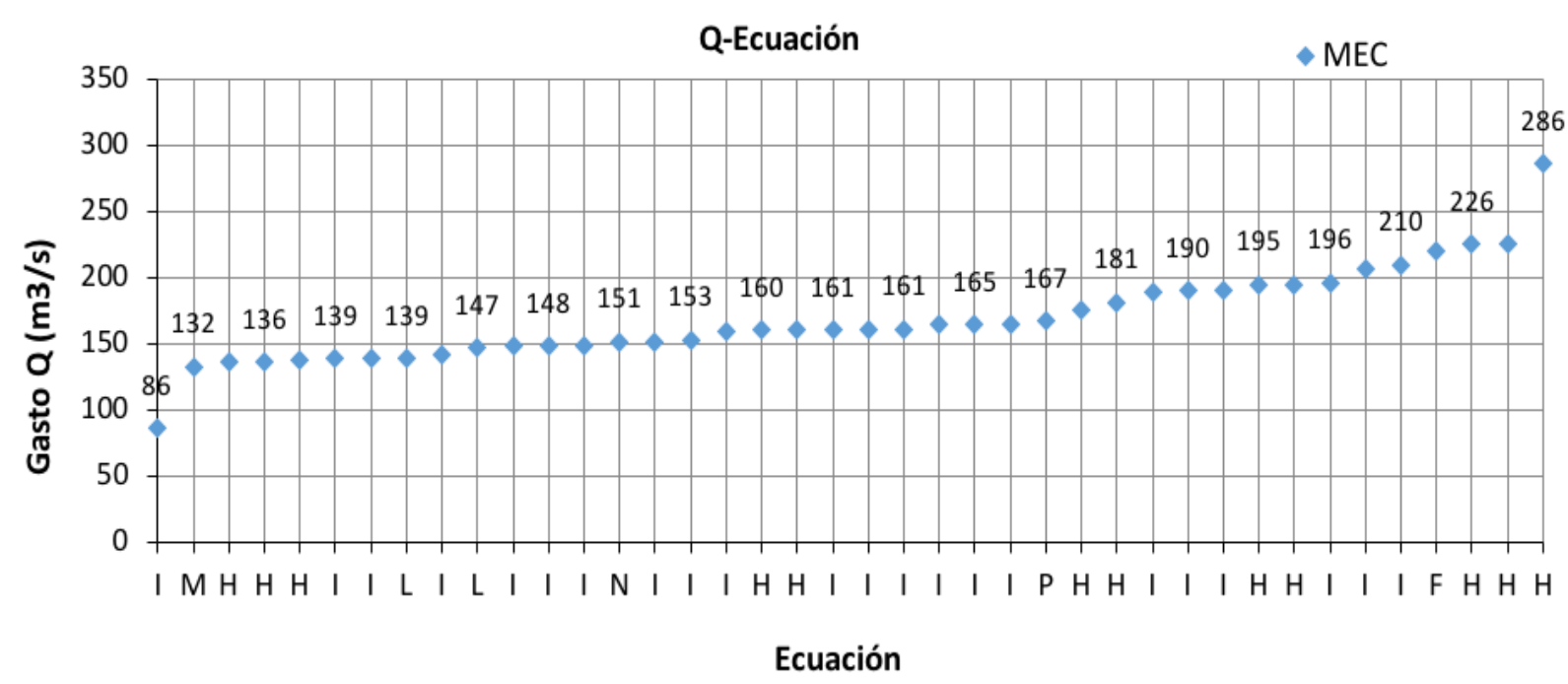

Figura 34. Ecuaciones de mejor ajuste para cada gasto calibrado.

Asimismo, se identifica que la integración de las metodologías expuestas permiten definir de mejor manera el parámetro de rugosidad compuesta además de las ecuaciones empíricas (Chie-Yen, 2002). Mediante la instrumentación hidráulica se pueden medir las velocidades en las zonas cercanas a la pared y que, complementados con mediciones de presión y caudal, permiten obtener el parámetro puntual de rugosidad equivalente integrando la ley logarítmica de velocidades, y las ecuaciones de Nikuradse y de Prandtl-Von Kármán para finalmente obtener la 


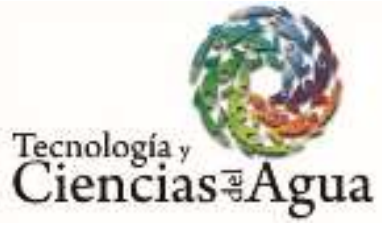

2022, Instituto Mexicano de Tecnología del Agua

Open Access bajo la licencia CC BY-NC-SA 4.0 (https://creativecommons.org/licenses/by-nc-sa/4.0/)

rugosidad compuesta representativa de la sección o del túnel. Esta metodología se puede aplicar a canales anchos con condiciones de régimen hidráulicamente rugoso y permanente, donde es posible integrar la relación Darcy-Weisbach y Manning (Aldama \& Ocón, 2012).

Se han realizado estudios previos experimentales para determinar la rugosidad compuesta en túneles en modelos en prototipo (Marengo \& Arreguín, 2008). En 2007 se llevó a cabo una investigación experimental, donde se comparó el flujo con cuatro modelos de túneles en sección baúl funcionando como canal con diferentes rugosidades y bajo diversas condiciones de escurrimiento. El prototipo estudió cuatro rugosidades asociadas: acrílico, lija, plástico y carpeta, que se asemejan al concreto hidráulico, concreto lanzado y roca en prototipo. De los resultados experimentales se obtuvieron las siguientes aproximaciones: 1) para la combinación acrílico-lija se obtuvo una mejor aproximación con la ecuación M de Ida-Engelund; 2) para la combinación acrílico-plástico, la ecuación de mejor ajuste fue la F de Felkel; 3) en la combinación acrílicotapete, el mejor ajuste fue la F de Felkel. Finalmente el autor recomendó que debido a la turbulencia que ocurre en la realidad se empleen las ecuaciones de Felkel (Ecuación F), la Ecuación de Yen (Ecuación H) y la Ecuación $\mathrm{N}$ de Yen también (ver Tabla 3). 


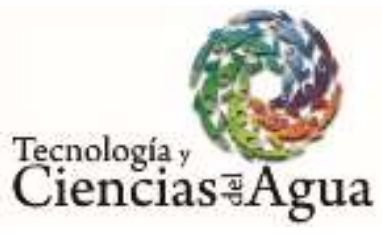

2022, Instituto Mexicano de Tecnología del Agua

Open Access bajo la licencia CC BY-NC-SA 4.0 (https://creativecommons.org/licenses/by-nc-sa/4.0/)

\section{Conclusiones}

El planteamiento de la metodología desarrollada permite estudiar la rugosidad compuesta a través de la relación que existe entre la superficie de contacto y el fluido (zona de capa límite); aplicar las teorías de capa límite de Prandtl-Von Kármán utilizando los perfiles de velocidad obtenidos de instrumentación hidráulica, con mediciones muy cercanas a la pared para el caso de estudio del túnel 1 de comunicación del río Grijalva. Los resultados obtenidos de la rugosidad equivalente de Nikuradse ks, y con la relación entre la ecuación de Darcy-Weisbach y de Manning se obtuvo una rugosidad de pared. Finalmente, con el modelo hidráulico general y las mediciones por sección se obtuvo una rugosidad representativa del túnel de $n=0.0178$. Se observó que a lo largo del túnel se mantiene el valor de rugosidad constante a excepción de los sitios donde se tiene cambio de revestimiento a concreto liso. También se encontró que la Ecuación I de Yen (Chie-Yen, 2002) es la que da mejor aproximación. Aun cuando la rugosidad compuesta no tenía una variación significativa en el rango de los gastos analizados (de 117 a $575 \mathrm{~m}^{3} / \mathrm{s}$ ), es recomendable dar continuación a la medición y aplicar la metodología para gastos mayores, pues las variaciones en la rugosidad solo podrían observarse si el gasto aumentara de manera significativa. También se 


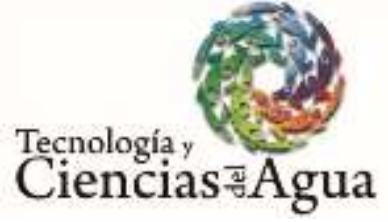

2022, Instituto Mexicano de Tecnología del Agua

Open Access bajo la licencia CC BY-NC-SA 4.0 (https://creativecommons.org/licenses/by-nc-sa/4.0/)

recomienda continuar con los registros de presión, gasto y velocidad para llevar a cabo la calibración con datos medidos.

La implementación de la instrumentación hidráulica en condiciones reales en obras de desvío es una herramienta importante de investigación para el estudio de la rugosidad compuesta para el diseño de estas obras, y mejorar así los métodos empíricos existentes. Estudios previos sobre estos temas se han realizado en modelos en prototipo, sin embargo, ello integra adicionalmente un parámetro de desviación por la escala.

El uso de la rugosidad compuesta, es decir, rugosidad combinada de concreto liso y concreto lanzado en los túneles permite asegurar un funcionamiento hidráulico más eficiente en las obras de desvío, garantizando una mejor capacidad de descarga hidráulica ante una contingencia durante la construcción de una presa, ya que permite integrar un mayor periodo de retorno $(\operatorname{Tr})$, al igual que mantener una mejor relación de beneficio/costo al no tener que revestir totalmente con concreto hidráulico todas las secciones.

De acuerdo con Marengo (2019), en los últimos años se ha prestado gran importancia a las condiciones de durabilidad y falla en las presas y sus obras temporales, como las de desvío. Se requiere revisar desde el punto de vista del marco técnico, social y legal. De igual forma, es necesario el desarrollo de métodos numéricos y técnicas computacionales que permitan tener un mejor conocimiento y entendimiento de los aspectos hidrológicos, geológicos y de los materiales, entre otros, por lo 
2022, Instituto Mexicano de Tecnología del Agua

Open Access bajo la licencia CC BY-NC-SA 4.0

(https://creativecommons.org/licenses/by-nc-sa/4.0/)

que se requieren serios esfuerzos en la implementación de instrumentación, así como definir de mejor manera el comportamiento estructural de las presas.

La consideración de la evaluación de los riesgos de falla de este tipo de obras en conjunto con los métodos de análisis de rugosidad compuesta aplicados en esta investigación permitirían aportar mejores elementos para el diseño de nuevos proyectos.

\section{Agradecimientos}

Al Laboratorio de Hidráulica de la Comisión Federal de Electricidad (CFE), y a los compañeros de instrumentación en laboratorio y campo. A la Coordinación de Proyectos Hidroeléctricos de la CFE por la oportunidad de colaborar dirigiendo diversos proyectos y estudios de instrumentación en obras hidráulicas. Al doctor Humberto Marengo como coordinador de Proyectos Hidroeléctricos y promotor de este tema. Al doctor Álvaro Aldama, quien asesoró éste y diversos proyectos en relación con los conceptos fundamentales de la mecánica de fluidos, que abrieron camino a esta investigación.

\section{Referencias}




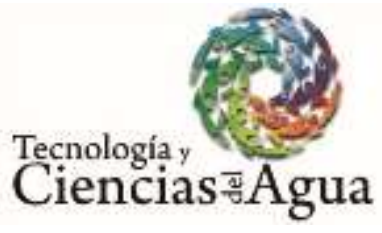

2022, Instituto Mexicano de Tecnología del Agua

Open Access bajo la licencia CC BY-NC-SA 4.0 (https://creativecommons.org/licenses/by-nc-sa/4.0/)

Aldama, A. A., \& Ocón, A. R. (enero-marzo, 2002). Resistencia al flujo en canales y límites de aplicabilidad de la fórmula Manning. Ingeniería Hidráulica en México, 17(1), 107-115.

Chie-Yen, B. F. (January 2002). Open Channel Flow Resistance. Journal of Hydraulic Engineering, 128(1). DOI: 10.1061/(ASCE)07339429(2002)128:1(20).

Chow, V. T. (1959). Open-Channel Hydraulics. Tokyo, Japón: McGraw Hill Kogakusha, LTD.

Marengo, H. (2019). Obras de desvío en proyectos hidráulicos, aspectos de diseño y construcción. Ciudad de México, México: Instituto de Ingeniería, Universidad Nacional Autónoma de México.

Marengo, H. (2011). Deslizamiento de tierra y roca que obstruyó el río Grijalva y su solución con túneles. Conferencia CFE. Tercer Seminario de Potamología, IMTA, Jiutepec, Morelos, México.

Marengo, H., \& Arreguín, F. (enero-marzo, 2008). Análisis hidráulico experimental en túneles de conducción en sección baúl trabajando como canal, considerando rugosidades compuestas. Ingeniería Hidráulica en México, 23(1), 21-44.

Rouse, H. (1965). Critical analysis of open channel resistance. Journal of Hydraulic Engineering, HY 4(91), 1-25.

Schlichting, H. (1979). Boundary-layer theory (7th ed.). New York, USA: McGraw-Hill. 


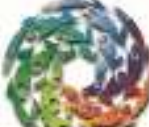

2022, Instituto Mexicano de Tecnología del Agua

Open Access bajo la licencia CC BY-NC-SA 4.0

(https://creativecommons.org/licenses/by-nc-sa/4.0/)

Sotelo, A. G. (2002). Hidráulica de canales. México, DF, México: Facultad de Ingeniería, Universidad Nacional Autónoma de México. 